\title{
BICYCLE AIR MONITORING MAP ENGINE
}

\author{
By: Kevin Worthington \\ Bachelor of Commerce (BComm) \\ Ryerson University, 2009
}

\begin{abstract}
A Professional Project Paper presented to Ryerson University in partial fulfillment of the requirement for the degree of

Master of Applied Science
\end{abstract}

In the Program of Environmental Applied Science and Management

Toronto, Ontario, Canada, 2015

(C) Kevin Worthington 2015 


\section{AUTHOR'S DECLARATION FOR ELECTRONIC SUBMISSION OF A PROFESSIONAL PROJECT PAPER}

I hereby declare that I am the sole author of this professional project paper. This is a true copy of the professional project paper, including any required final revisions. I authorize Ryerson University to lend this professional project paper to other institutions or individuals for the purpose of scholarly research I further authorize Ryerson University to reproduce this professional project paper by photocopying or by other means, in total or in part, at the request of other institutions or individuals for the purpose of scholarly research. I understand that my professional project paper may be made electronically available to the public 
Bicycle Air Monitoring Map Engine

Master of Applied Science 2015

Kevin Worthington

Environmental Applied Science and Management

Ryerson University

\section{Abstract}

Advancements in technology has brought increasingly affordable and more portable air quality sensors to market. These sensors are giving rise to citizen science opportunities where members of the public are able to collect air quality measurements of their surroundings. Managing and sharing this volunteered geographic information (VGI) with the public is made possible through web-based geographic information systems. This project demonstrates how such a system can be developed to manage fine particulate matter $\left(\mathrm{PM}_{2.5}\right)$ data collected by bicyclists in Hamilton and Toronto Ontario. Key features built into the application include an administration console, data visualization engine, direction service and adjustments toolkit. The crowdsourced results are paired with the closest fixed air quality monitor and meteorological data, allowing nearby conditions during sample collection to be accounted for. This project complements regional fixed air quality monitors but attempting to fill the gap between them to create awareness of local $\mathrm{PM}_{2.5}$ issues. 


\section{Acknowledgements}

To my supervisors Dr. Eric Vaz and Dr. Raktim Mitra, for your continued support throughout this project.

Julian Morales, Climate Services Specialist, Environment Canada, for your help in securing a feed to include the closest available historical weather data when uploading collected samples.

Tony Munoz Supervisor, Air Quality Assessment and Reporting Unit, Ministry of Environment and Climate Change, for coordinating the correlation analysis between the 5030 SHARP and the Dylos DC1700.

Michael Luciani, Field Technician, Terrestrial Assessment and Field Services Unit, Ministry of Environment and Climate Change, for your professionalism and enthusiasm in collecting data as part of the correlation analysis. Deploying the Dylos unit to the roof on those frigid winter days and sending me the data, made this part of the study possible.

Alyre Melanson, Coordinator, Field Operations AQI, Ministry of the Environment and Climate Change, for giving us access to the roof where the correlation analysis was conducted and helping us collect the data from the terminal.

Natalia Mykhaylova, PhD Researcher, University of Toronto, for all your suggestions regarding the correlation analysis and your website feedback.

Denis J. Corr, Ph.D., Corr Research, for your consultative support.

Daniel Jakubek, GIS and Map Librarian, Ryerson University Library, for your assistance in retrieving research material on several occasions with exceptionally fast turnaround.

Joe Osborne, Legal Director, Group Against Smog and Pollution, for your walkthrough of the clusters colorization approach used at GASP.

Karmyn Guthrie, Web Developer, Group Against Smog and Pollution, for your help in understanding the GASP BAM map application design.

Paul Perham, Engineer, Dylos Corp., for sharing your insights into the Dylos unit.

Lynda Lukasik, Executive Director, Environment Hamilton, for allowing me the opportunity to develop the BAM Map Engine.

Heather Marshall, DeTOx Toronto Campaigner, Toronto Environmental Alliance, for coordinating a similar study in Toronto and bringing me onboard.

Thank you to my friends who helped test the application and provide me with valuable feedback.

I would also like to thank all the volunteers who have taken the time to collect air quality data. 


\section{Dedication}

This thesis project is dedicated to my Mother. Your struggle with asthma is my motivation for furthering our understanding of the air we breathe. 


\section{Table of Contents}

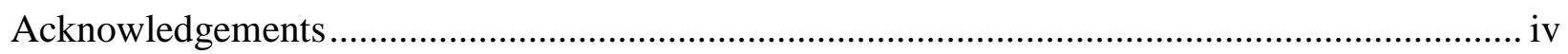

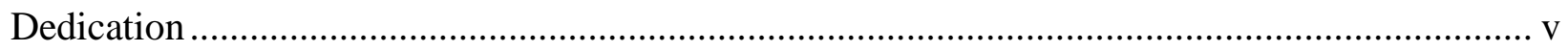

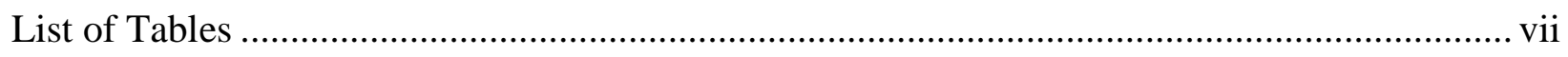

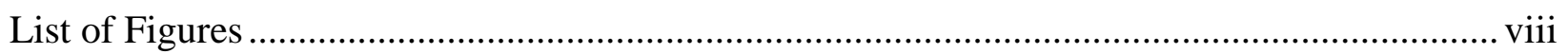

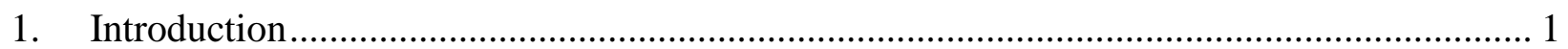

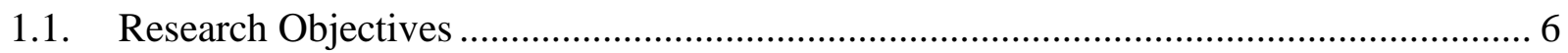

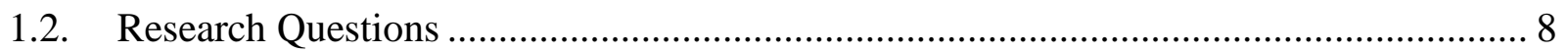

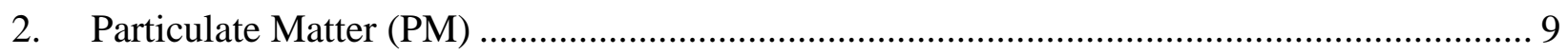

2.1. Sources of Particulate Matter ................................................................................ 9

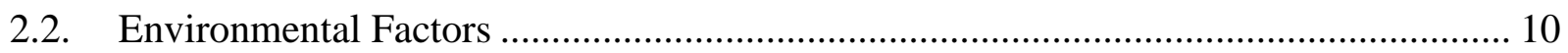

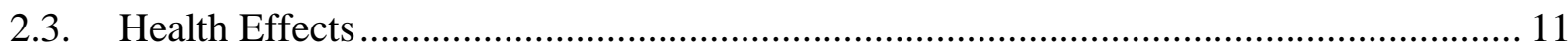

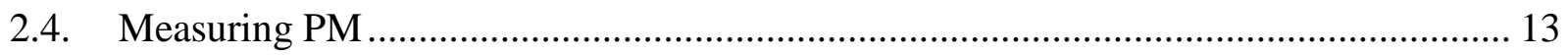

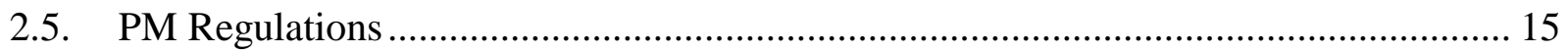

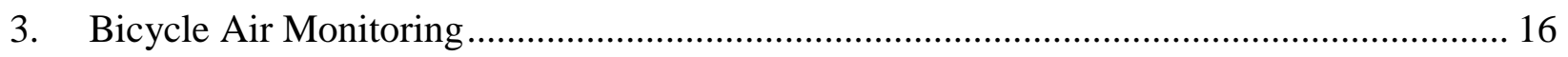

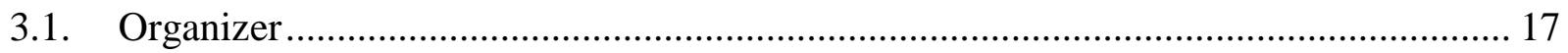

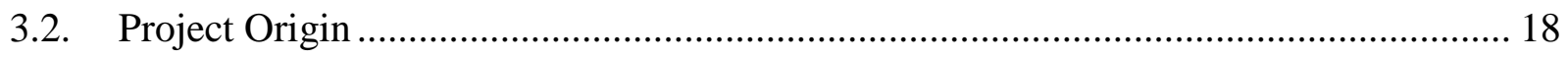

3.3. Volunteered Geographic Information ................................................................. 19

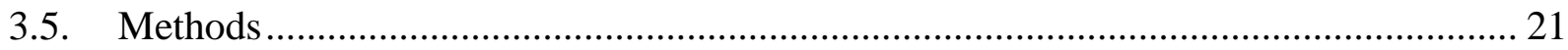

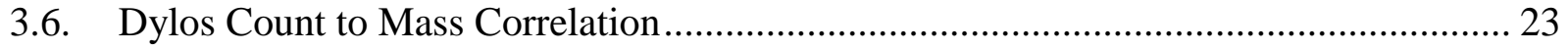

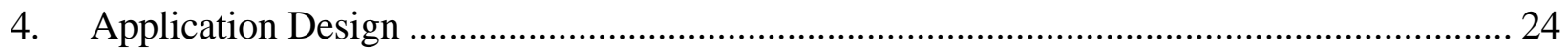

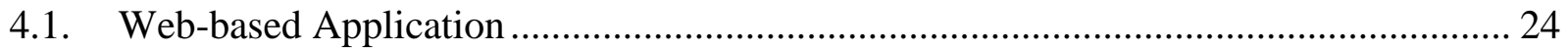

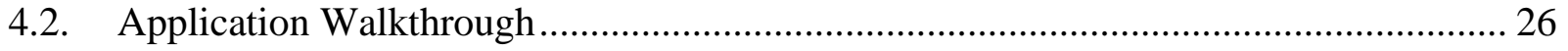

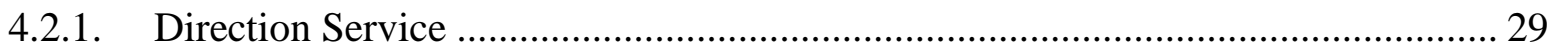

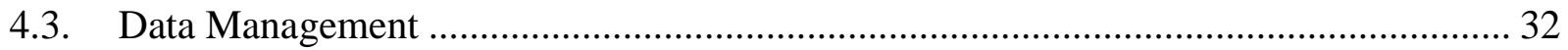

4.3.1. Publishing Data from Devices ........................................................................ 32

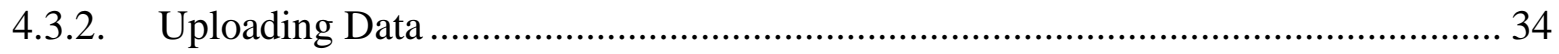

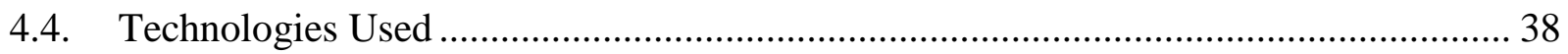

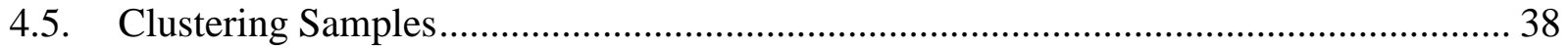

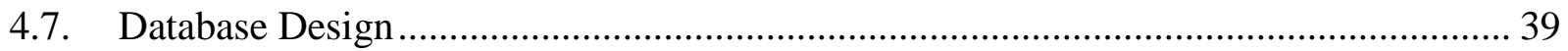

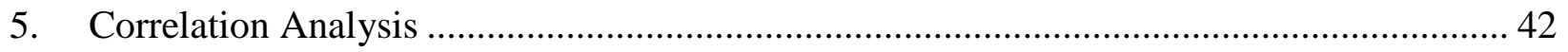

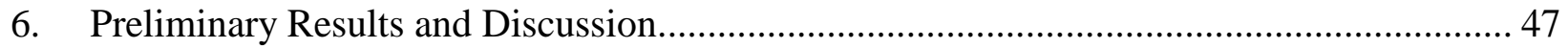

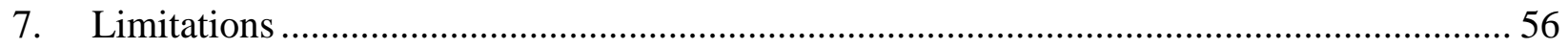

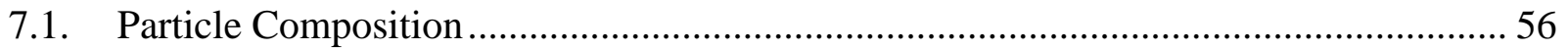




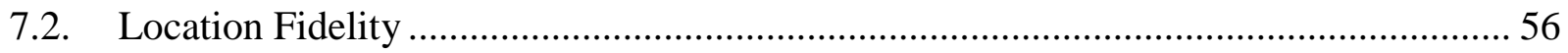

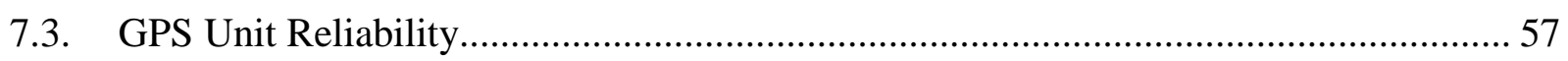

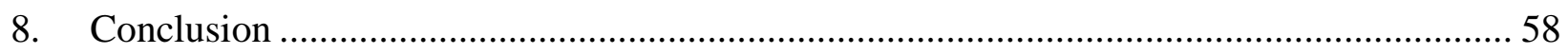

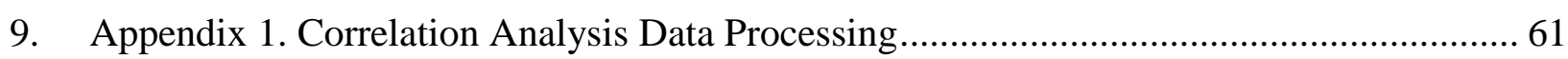

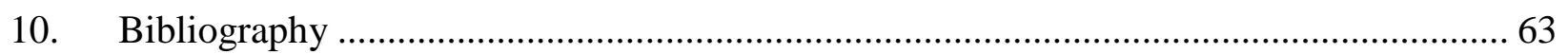

\section{List of Tables}

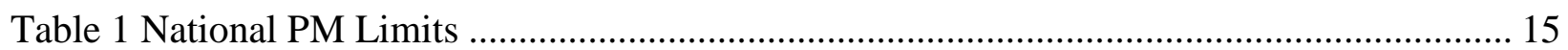

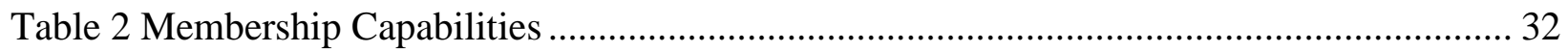

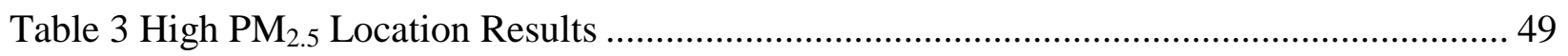

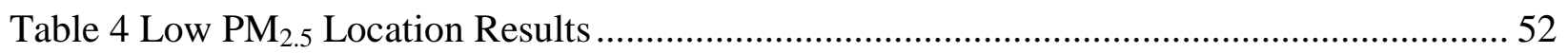




\section{List of Figures}

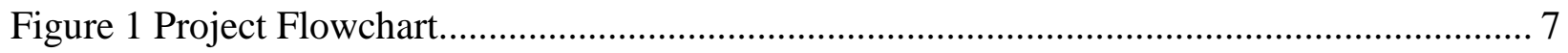

Figure 2 Bicycle Air Monitoring Map Engine Overview ....................................................... 22

Figure 3 Dylos DC1700 Mounted near air inlet of 5030 SHARP at 125 Resources Rd. Toronto 24

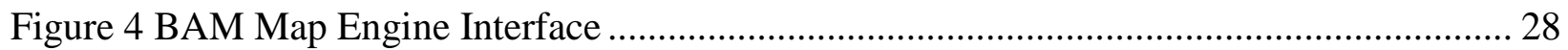

Figure 5 BAM Map Engine Direction Interface ……………................................................. 31

Figure 6 DylosLogger 1.6 Download History Window............................................................ 33

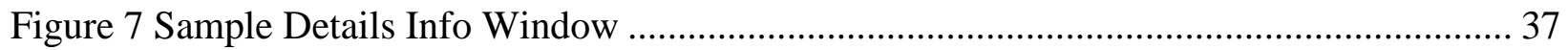

Figure 8 Database Design ................................................................................................. 41

Figure 9 Dylos DC1700 to SHARP 5030 Correlation............................................................ 44

Figure 10 Dylos DC1700 PM Detection vs. SHARP 5030 PM \& Relative Humidity Over Time

Figure 11 Dylos DC1700 PM Detection vs. 5030 SHARP PM \& Correlated Value .................... 45

Figure 12 Coefficients of Determination Matrix ......................................................................... 46

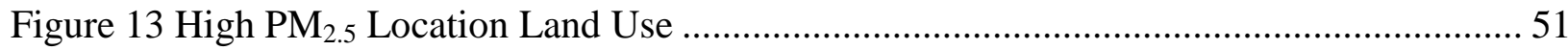

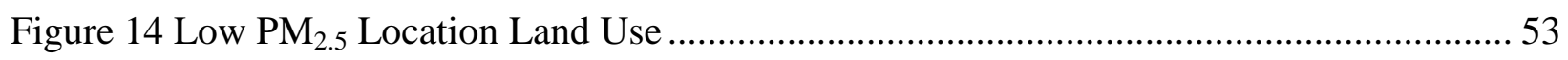

Figure 15 Land Use Between High and Low PM Locations ...................................................... 54 


\section{Introduction}

Clean air is an essential part of living a healthy life; however, many of us are unaware of the quality of the air we breathe on a daily bases. Many potential air pollutants exist including Ozone, Carbon Monoxide, Nitrogen Oxides, Sulfur Dioxide, Lead and Particulate Matter (PM) (USEPA, 2012). $\mathrm{PM}_{2.5}$ is of particular importance as an air pollutant due to its ability to bypass nasal protection and be breathed more deeply into the lungs (Pope \& Dockery, 2006). Health effects attributed to $\mathrm{PM}_{2.5}$ inhalation include cardiovascular and respiratory diseases such as strokes, chronic obstructive pulmonary disease, asthma attacks, acute bronchitis and lung cancer (WHO, 2014).

Worldwide 3.7 million premature deaths were estimated in 2012 due to small particulate matter 10 microns or less in diameter (World Heath Organization, 2014). While the majority of these premature deaths occur in low and middle-income countries (such as the Western Pacific and South-East Asia), in Canada it is estimated that 3,200 and 26,000 premature deaths are attributed to acute and chronic exposure of $\mathrm{PM}_{2.5}$ and Ozone respectively for 2015 (Candian Medical Association, 2008). It is estimated that 40 Hamilton and 897 Toronto residents die from $\mathrm{PM}_{2.5}$ inhalation each year (SENES Consultants Limited, 2012) (Campbell \& Gower, 2014).

Measuring the level of air quality impairment is in large part performed by fixed air quality monitors. Three fixed air quality monitors exist for all of Hamilton and 4 for the entire Greater Toronto Area (Ministry of the Environement and Climate Change, 2010), measuring multiple pollutant levels on an hourly basis. These fixed area quality monitors are operated by the Ministry of the Environment and Climate Change (MOECC) who manage an extensive network across the province of Ontario, comprised of 40 fixed air quality monitors. The 
placement of these fixed air quality monitors offers a reliable regional perspective of air pollution levels; however, localized levels of pollutants are not always representative of the region. The Environmental Commissioner of Ontario (ECO) did an independent study comparing the downtown air monitoring station in Toronto to ground-level measurements and registered an Air Quality Index (AQI) value of "very poor" compared to the "good" level reported by the fixed monitor (ECO, 2011). It has been shown that an exponential decrease in particle counts can occur with increasing distance downwind from roadways (Brugge, Durant, \& Rioux, 2007), suggesting that fixed stations placed futher away from locations would detect less particles. The high costs associated with fixed quality monitors limits their widespread deployment, though with areas of $1,138 \mathrm{~km}^{2}$ and $7,124 \mathrm{~km}^{2}$ for Hamilton and the Greater Toronto Area respectively, 3 and 4 fixed air quality monitors may not provide measurements representative of the entire community (Health Canada, 2013).

To fill in the gaps present in the fixed air pollution monitoring land-use regression (LUR) models have been employed, using multiple spatial layers along with select air quality samples to confirm results. A LUR model developed for New York City using more than 25 variables at 5 different buffer distances was able to predict variations in $\mathrm{PM}_{2.5}$ with $61 \%$ and $64 \%$ reliability (Ross, Jerrett, Ito, Tempalski, \& Thurston, 2007). In Los Angeles, a LUR model was able to achieve 69\% accuracy using 3 variables at 2 distances (traffic density, $500 \mathrm{~m}$; industrial land area and government land area, $5000 \mathrm{~m}$ ) (Moore, Jerrett, Mack, \& Künzli, 2007). While LUR is a cost-effective solution offering a decent estimate of $\mathrm{PM}_{2.5}$ under specific conditions, the need for ground-level $\mathrm{PM}_{2.5}$ measurements is essential to set-up model. As well, it has been shown that models used to estimate PM concentrations have many limitations including the exclusion of transient sources of PM such as those from unpaved roads, prescribed burnings and construction 
site sources (Health Canada, 2013). The seasonality of PM must also be considered, as secondary particulates during summer months may account for $50 \%$ of measured levels which are not yet incorporated as part of model estimates (Health Canada, 2013). All in all, models may be underestimating PM levels (Health Canada, 2013), supporting the need to collect ground-level air quality measurements.

Mobile air quality monitors enable air quality measurements to be taken anywhere, complementing the fixed monitors (Rotek Environmental Inc., 2011). A mobile vehicle has been outfitted with sensors to conduct air quality measurements in Hamilton (Rotek Environmental Inc., 2011) and more recently volunteers bicyclists have been recruited to assist with the air quality data sampling efforts (Environment Hamilton, 2014). Fourteen personal air quality units measuring particle counts with size ranges of $>0.5$ and $<2.5 \mu \mathrm{m}$ have been purchased by Environment Hamilton (EH) and 5 by the Toronto Environmental Alliance (TEA). These personal air quality units are being lent to volunteers along with GPS units for a week of data collecting and the information being made publically available using an interactive map developed for this project. The coordination of these citizen scientists is being performed by EH under the project title Bicycle Air Monitoring (BAM).

The use of bicyclists as part of this study is a novel approach. There are many reasons why bicycles make sense for such as study. Firstly, bicycling has been deemed the most energy efficient mode of transport (over walking) (Banister, 2011), generating no pollution (except during manufacturing). Bicyclists are exerting higher levels of activity and subsequent breathing rates, increasing their susceptibility to air pollution 2 to 4 times that of vehicle passengers (Sarah Jarjour, 2013), making the air they breathe that much more important. In Toronto $68 \%$ of surveyed individuals indicated poor air quality as an obstacle to encouraging more cycling (City 
of Toronto, 2001), which demonstrates the urgence of addressing the air pollution issue. Bicycling is also gaining in popularity in Toronto with a 6\% increase between 1999 and 2009 for people older than 16 years of age (City of Toronto, 2009), increasing the number of individuals inadvertently being exposed to higher levels of $\mathrm{PM}_{2.5}$. Lastly, bicyclists are the ambassadors of active transport, proving that there are alternative methods of transportation which do not consumer nonrenewable resources. The adoption of active transport is of critical importance as reports show that $46 \%$ of Canadians are physically inactive (Employment and Social Development Canada, 2012) and 62\% of Canadian were reported as either overweight or obese (Employment and Social Development Canada, 2012). It has been shown that routes less than $10 \mathrm{~km}$ in urban areas are often fastest when bicycled (City of Toronto, 2000) and that most car trips are less than $10 \mathrm{~km}$ (Canadian Broadcasting Corporation, 2008). Despite this, travel using motor vehicles represents highest transportation mode at 65\% (City of Toronto, 2000). Such reliance on motor vehicles starts at a young age, as it has been revealed that $37 \%$ of Toronto students between 11-12 years of age, living within $3.2 \mathrm{~km}$ from schools, took either a private vehicle, school bus or public transit (Mitra \& Faulkner, 2012).

Advances in technology have given rise to more sophisticated internet applications (Pengnate, 2013). Beyond Web 2.0 (where traditional web users are transformed from consumers to producers), the Semantic Web or Web 3.0 exists. Web 3.0 is where this shared information is put into context by adding additional information to it, such as the inclusion of a spatial component. Maps of our surroundings are being generated by non-professionals or "citizen scientists" described as Volunteered Geographic information (VGI) (Goodchild, 2007). These maps are revealing a level of detail not possible by government or private organizations. In the 
hands of government organizations such dynamic maps would support better decision making for the well being of its citizens, referred to as "smart cities" (Paskaleva, 2009).

The BAM Map Engine is a feature-rich Web-based Geographic Information System (WebGIS) developed as part of this project to managed the data collected by the BAM volunteers. By pairing air quality measurements, with GPS locations, a high resolution visual representation of the spatial distribution of $\mathrm{PM}_{2.5}$ is created. This geolocated $\mathrm{PM}_{2.5}$ information automatically updates aggregated clusters on the map when uploaded, to help identify chronically poor air quality locations. To access this information all that is required is an internet connection and a modern browser. Volunteers are empowered to upload the information themselves (from their personal computer) to see their contributions plotted on a map and in chart form, showing where high and low $\mathrm{PM}_{2.5}$ counts exists along their route. Aggregated $\mathrm{PM}_{2.5}$ information is shared anonymously, and allows others to avoid these identified pollution hotspots.

A high resolution $\mathrm{PM}_{2.5}$ map offers many uses beyond the avoidance of $\mathrm{PM}_{2.5}$ hotspots by bicyclists. The placement of facilities targeting active and sensitive individuals such as bike lanes, daycares, schools, retirement homes, etc can utilize this data in their siting considerations. Health studies would benefit from having data revealing $\mathrm{PM}_{2.5}$ levels in specific locations as it would assist in understanding the local exposure of individuals. As well, property valuation can benefit from this data (Kenneth Y \& Greenstones, 1998), as indoor air pollution is largely influenced by the outdoors (Morawska, Thomas, Gilbert, Greenaway, \& Rijnders, 1999). Recently detected increases of $\mathrm{PM}_{2.5}$ in the Hamilton air (Clear Air Hamilton, 2013) further necessitates the need for better awareness and understanding of the $\mathrm{PM}_{2.5}$ issue to support sustainable urban environments. 


\subsection{Research Objectives}

1. The main focus of this project is to share the collected air quality data from BAM using a publically accessible interactive map. This web-based map will be capable of data manage, analysis and visualization. Once complete, the map will be available online to support public awareness at www.bicyclingroute.com.

2. A recommendation by the Air Quality Task Force (AQTF) is to provide a tool for mapping real-time air quality conditions facilitating the selection of routes to minimize exposure to air pollution (Clear Air Hamilton, 2013). By including a direction service as part of this project which quantifies $\mathrm{PM}_{2.5}$ levels for route options, bicyclist should be able minimize their personal exposure to air pollution by selecting the cleanest air route.

3. The use of data visualization will highlight areas with elevated levels of $\mathbf{P M}_{2.5}$ which can help support policy targeted towards improving urban air quality.

See Figure 1 Project Flowchart for a visual representation of the tasks accomplished for this project. 


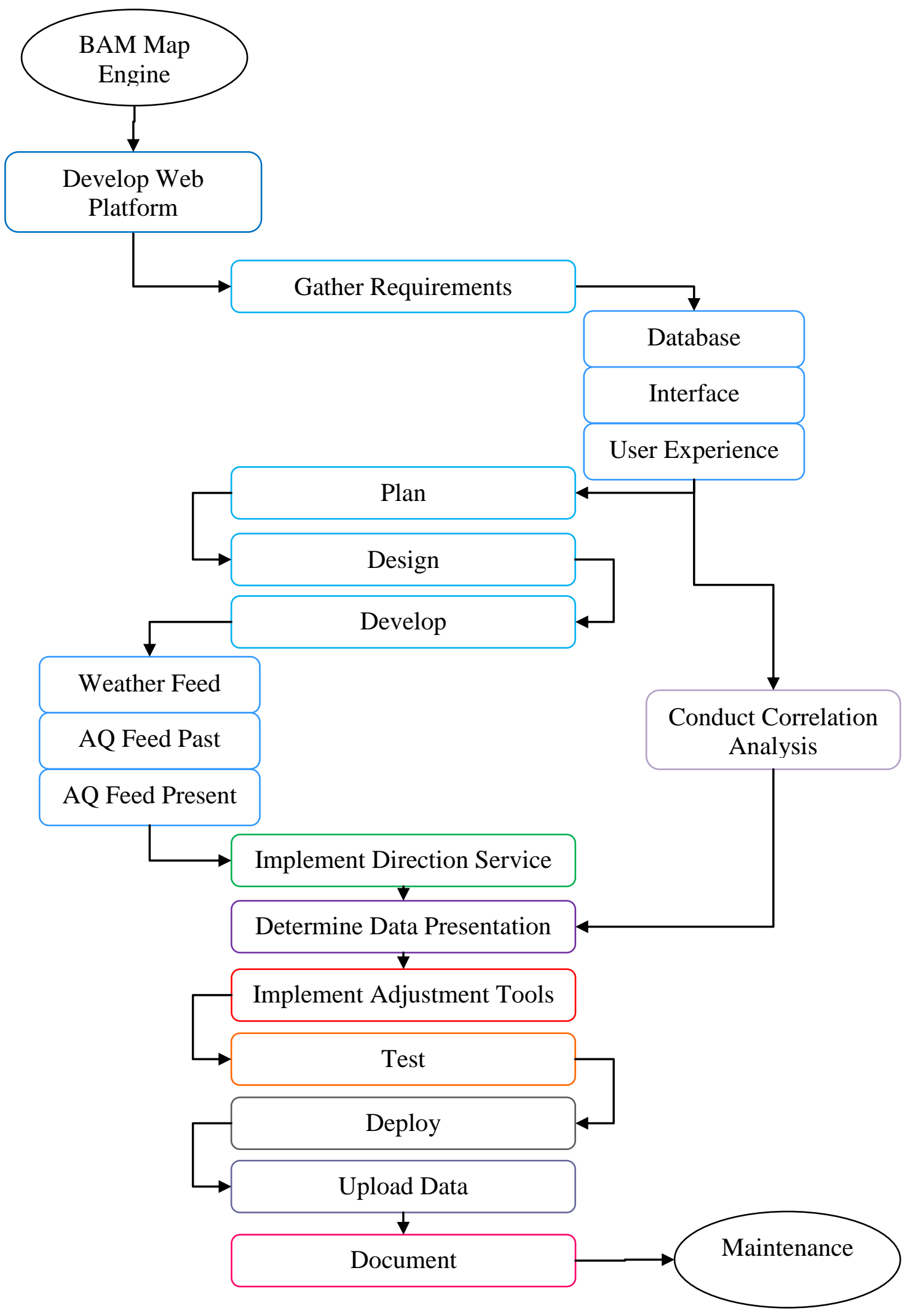

Figure 1 Project Flowchart 


\subsection{Research Questions}

Using the data collected through the BAM project, two supplementary questions will be explored:

1. Where are the areas of chronically poor air quality in the city of Hamilton and what are their sources?

2. Do personal Air Quality Monitors provide an effective method of $\mathrm{PM}_{2.5}$ measurement? 


\section{Particulate Matter (PM)}

$\mathrm{PM}$ is one of 6 major air pollutants which include, sulphur dioxide $\left(\mathrm{SO}_{2}\right)$, nitrogen dioxide $\left(\mathrm{NO}_{2}\right)$, carbon monoxide $(\mathrm{CO})$, lead $(\mathrm{Pb})$, and ozone $\left(\mathrm{O}_{3}\right)$ (Langner, Draheim, \& Endlicher, 2011). The composition of PM may incorporate one or more of the major pollutants as well as other organic chemicals, metals, soil and dust particles, each with varying degrees of toxicity (Kelly \& Fussell, 2012). Despite the heterogeneity of PM, general health guidelines have been established. PM consists of airborne particles in solid or liquid, which vary in shape and size. PM is measured in microns $(\mu \mathrm{m})$ with 3 main size ranges, $\mathrm{PM}_{10}, \mathrm{PM}_{2.5}$ and $\mathrm{UFP} . \mathrm{PM}_{10}$ is known as inhalable coarse particulate with a size range of less than $10 \mu \mathrm{m}$ and greater than 2.5 $\mu \mathrm{m}$ in aerodynamic diameter (USEPA, 2013), able to bypass nasal protection (the thoracic region) (WHO, 2005). $\mathrm{PM}_{2.5}$ is known as fine particulate with a size range of $2.5 \mu \mathrm{m}$ or smaller in aerodynamic diameter (USEPA, 2013), able to reach the alveoli in the lungs (WHO, 2005). A subset of $\mathrm{PM}_{2.5}$ also exists known as ultrafine particulate (UFP) or $\mathrm{PM}_{0.1}$ measuring less than 0.1 $\mu \mathrm{m}$ in aerodynamic diameter or $100 \mathrm{~nm}$ (USEPA, 2005), able to be transported into the bloodstream (United Nations, 2009). The size of PM also affects its resident time and absorption potential. Longer particles have shorter resistance times, with $\mathrm{PM}_{10}$ able to remain in the atmosphere for a few hours to days and $\mathrm{PM}_{2.5}$ able to remain in the atmosphere for days to weeks (Health Canada, 2013). In addition to staying in the air longer, smaller particles have more surface area relative to mass compared to larger particles, increasing their potential to absorb other pollutants (Health Canada, 2013).

\subsection{Sources of Particulate Matter}

PM can originate from natural and anthropogenic sources. Some natural sources of PM include volcano eruptions, forest fires, sea spray and dust storms. While anthropogenic source of 
PM include biomass combustion and waste incineration, industrial processes, vehicular emissions, road abrasion and resuspension of dust (Schwarze, et al., 2006). More than two thirds of $\mathrm{PM}_{2.5}$ can be traced to anthropogenic sources (WHO, 2005) and with increased levels of urbanization in the Greater Toronto Area (Vaz \& Jokar Arsanjani, 2015), $\mathrm{PM}_{2.5}$ will continue to plague our air. Many sources can be classified as point, non-point and line sources. An example of a point source would be a smoke stack or tail pipe. Non-point sources occur during the long range transport of point sources making the root sources difficult to discern (NOAA, 2008). A line source represents a channel where elevated levels of PM exist such as a roadway. Sources of PM can be either primary; such as direct exhaust or secondary; such as when gases are combined and nucleate. PM concentrations and composition vary spatially and temporally (Langner, Draheim, \& Endlicher, 2011). A study done in Berlin revealed the highest $\mathrm{PM}_{10}$ levels were found at the curbside of roads (Langner, Draheim, \& Endlicher, 2011). In most urban roadway sites, up to $50 \%$ and $60 \%$ increases in $\mathrm{PM}_{10}$ and $\mathrm{PM}_{2.5}$ concentrations occur midweek, relative to Sunday (Health Canada, 2013). Each weekday, significant increases in $\mathrm{PM}_{10}$ levels were measured in the morning rush hour, with a second peak of $\mathrm{PM}_{10}$ during the late evening. The size, age and fuel used in vehicles has a significant effect on the amount of exhaust, with diesel burning vehicles releasing 15 times more emissions per liter of fuel burned (Yang, 2012).

\subsection{Environmental Factors}

There are many influencing factors affecting the levels of PM measured such as the weather, terrain, and the built environment. Temperature plays a large role in the mixing layer height affecting air exchange. A lower mixing layer reduces the potential for air exchange which can increase PM concentrations (Langner, Draheim, \& Endlicher, 2011). As smaller aerodynamic diameters of PM can allow particles to remain suspended in the air for weeks 
making wind speeds a huge impact on the transport of these particles. A $5 \mathrm{~km} / \mathrm{h}$ wind can decrease $\mathrm{PM}_{2.5}$ concentrations by $10 \%$, with exponential decreases in air pollutants as wind speeds increase (Strauss, 2012). Low wind velocities with high air stability increases air pollution levels as less air exchange occurs (Langner, Draheim, \& Endlicher, 2011). This stable air can cause air inversions further increasing levels of PM if cool air becomes trapped below a layer of warm air in the atmosphere reducing air refresh (Clean Air Hamilton, 2014).

Precipitation has been shown to wash pollution out of the air through either rain or snow events. A weak precipitation with less than $0.1 \mathrm{~mm} / \mathrm{h}$ can reduce aerosols below-cloud by $50-80 \%$ during a 4 h period (Zhang, Michelangeli, \& Taylor, 2004). Areas located in basins have less air exchange which can lead to increased PM levels (Langner, Draheim, \& Endlicher, 2011).

The building heights along urban corridors are known as street canyons which have shown to have higher pollutant levels due to increased traffic emissions and reduced ventilation from lack of air dispersion (Vardoulakis, Fisher, \& Gonzalez-Flesca, 2003). When the wind blows perpendicular to the street canyon, the leeward side of the street (opposite the windward side) may have 5-10 times the pollution concentrations of those found on the opposite side of the street (Vardoulakis, Fisher, \& Gonzalez-Flesca, 2003).

\subsection{Health Effects}

The pathway of exposure to PM is inhalation. Particles small enough to reach the lower part of the respiratory airways can cause lung issues and heart complications (Cheng, Jiang, Fajardo, Wang, \& Hao, 2013). Lung issues associated with PM can occur in the short-term and include difficulty breathing, coughing, aggravated asthma and bronchitis (Health Canada, 2013). Over the long term PM can cause chronic obstructive pulmonary disease (COPD) (WHO, 2005) which causes inflammation of the lungs limiting air flow (Bhatt \& Dransfield, 2013). Heart 
complications are more long-term and include arrhythmias, heart attacks and coronary artery disease. Ultimately, premature death may result from short and long term aliments depending on the severity. The most vulnerable people to PM are children, the elderly, and those with asthma (American Academy of Pediatrics, 2004).

In scientific studies done in Canada, Europe and the United States increased rates of respiratory-related illness in children living in high road traffic areas have been found (Government of Canada, 2012). Infants and children are among the most susceptible to air pollutants given their higher minute ventilation and higher levels of physical activity (American Academy of Pediatrics, 2004), although elderly individuals are at a slightly higher risk compared to the rest of the population (Health Canada, 2013). Cyclists are also exerting higher levels of activity and subsequent breathing rates, increasing their susceptibility to air pollution 2 to 4 times that of vehicle passengers (Sarah Jarjour, 2013). A study done in the Netherlands measuring $\mathrm{PM}_{2.5}$ exposure between transport modes revealed that a cyclist exposure to $\mathrm{PM}_{2.5}$ is the highest compared to bus and personal vehicle passengers due to their increased breathing rate (Zuurbier, et al., 2010). A six city study in the United States revealed a $1.5 \%$ increase in mortality per 10 $\mu \mathrm{g} / \mathrm{m}^{3}$ increase in $\mathrm{PM}_{2.5}$ exposure (Health Canada, 2013). Increased risk of lung cancer has also been found for mixed occupational exposure to diesel engine exhaust (Ban-Weiss, Mclaughlin, Harley, Kean, \& Grosjean, 2008). With awareness and conscious avoidance of elevated levels of PM the risk of such ailments would likely be reduced. Brook et al, have found that reductions in $\mathrm{PM}_{2.5}$ exposure can decrease the risk cardiovascular mortality when done for several months to a few years (Brook, et al., 2010). Environmental health is also compromised by heightened PM levels as vegetation can experience reductions in photosynthesis and open water can acidify from acid rain. 


\subsection{Measuring PM}

The detection of PM levels in the air can be achieved using either direct or indirect methods with values usually represented in mass. The direct method is a manual process involving a pre-weighted filter with a constant air flow-rate drawn through it for a specific period of time, usually 24 hours (Health Canada, 2013). The weight of the soiled filter after the sample period minus the original filter weight gives you the mass of PM in the air for that period. The hi-vol sampler was the standard direct method of measuring Total Suspended Particles (TSP) in Canada and was later equipped with a size selective inlet (SSI), allowing the omission of PM larger then a certain size (Health Canada, 2013). The dichotomous sampler measures $\mathrm{PM}_{10}$ and $\mathrm{PM}_{2.5}$ by first omitting particles large then $10 \mu \mathrm{m}$ and then splitting the remainder at the $2.5 \mu \mathrm{m}$ mark (Health Canada, 2013). A 50\% cut point is used to allow PM of a specific size to enter the inlet of direct method sampling devices. This $\mathrm{D}_{50}$ cut point is only accurate at specific flow rates and can lead to differing mass values, especially with $\mathrm{PM}_{10}$ detection due to the larger particle size and subsequent weight.

Indirect methods are more automated and include a number of different devices (Health Canada, 2013). The Beta Attenuation Monitor is a popular device used in Europe and Japan which allows real-time measurements to be collected at hourly intervals (Health Canada, 2013). It uses a cyclone of air to separate out larger particles allowing smaller ones to land on a filter tape . The filter tape is then passed through beta rays to determine particle counts, which shifts exposing a clean area on the tape for the next sample to be collected. In Ontario, the Thermo Scientific TEOM 1400AB/SES was used until 2012, replaced by the Thermo Scientific 5030 SHARP which was designed by the USEPA in 2009 (OMECC, 2014). 
While the methods and devices previously mentioned are costly and time consuming, advances in technology have given rise to consumer devices able to monitor PM at more affordable prices. Companies like Dylos have a number of air quality monitors which use an optical particle counter to determine counts at given size fractions. It should be noted that the comparability of PM measurements collected from different devices has a number of considerations including maintenance schedule adherence and operation methods (Health Canada, 2013).

Since 1984, $\mathrm{PM}_{10}$ and $\mathrm{PM}_{2.5}$ monitoring programs have been in operation in Canada, known as the National Air Pollution Surveillance (NAPS) program (Health Canada, 2013). Findings from NAPS data reveal cities have the highest $\mathrm{PM}_{2.5}$ concentrations (using $90^{\text {th }}$ percentiles means) include Montréal, Toronto, Hamilton, Windsor, Walpole Island and Vancouver (Health Canada, 2013). 


\subsection{PM Regulations}

National differences in regulation limits exist for outdoor PM as seen in Table 1 National PM Limits. In Ontario, previous to the Canadian Ambient Air Quality Standards (CAAQS), the Canada-wide Standards (CWS) existed, which the province was a signatory of and established non-binding measures known as the Ambient Air Quality Criteria (AAQCs) (ECO, 2015). As of this writing, the higher AAQCs $\mathrm{PM}_{2.5}$ value of $30 \mu \mathrm{g} / \mathrm{m}^{3}$ compared to the national CAAQS is to be implemented by the province, but had not yet been done so (ECO, 2015). As long-term exposure to $\mathrm{PM}_{10}$ did not show an association with health effects, it was removed from the AAQC (EPA, 2006).

Table 1 National PM Limits

\begin{tabular}{|c|c|c|c|c|}
\hline Country/Org & $\begin{array}{l}\text { Pollutant/ } \\
\text { Average Period }\end{array}$ & Concentration & $\begin{array}{l}\text { Date of } \\
\text { Enforcement }\end{array}$ & Source \\
\hline $\begin{array}{l}\text { European } \\
\text { Commission }\end{array}$ & $\mathrm{PM}_{2.5}$ Annual & $25 \mu \mathrm{g} / \mathrm{m}^{3}$ & January 1,2015 & $\begin{array}{l}\text { (European Commission, } \\
\text { 2014) }\end{array}$ \\
\hline $\begin{array}{l}\text { European } \\
\text { Commission }\end{array}$ & $\begin{array}{l}\mathrm{PM}_{10} \\
24 \text { hour }\end{array}$ & $40 \mu \mathrm{g} / \mathrm{m}^{3}$ & January 1,2005 & $\begin{array}{l}\text { (European Commission, } \\
\text { 2014) }\end{array}$ \\
\hline $\begin{array}{l}\text { European } \\
\text { Commission }\end{array}$ & $\begin{array}{l}\mathrm{PM}_{10} \\
\text { Annual }\end{array}$ & $50 \mu \mathrm{g} / \mathrm{m}^{3}$ & January 1,2005 & $\begin{array}{l}\text { (European Commission, } \\
\text { 2014) }\end{array}$ \\
\hline $\begin{array}{l}\text { United States } \\
\text { (EPA) }\end{array}$ & $\begin{array}{l}\mathrm{PM}_{2.5} \\
\text { Annual }\end{array}$ & $12 \mu \mathrm{g} / \mathrm{m}^{3}$ & $\begin{array}{l}\text { December 14, } \\
2012\end{array}$ & $\begin{array}{l}\text { (United States Environmental } \\
\text { Protection Agency, 2012) }\end{array}$ \\
\hline $\begin{array}{l}\text { United States } \\
\text { (EPA) }\end{array}$ & $\begin{array}{l}\mathrm{PM}_{2.5} \\
24 \text { hour }\end{array}$ & $35 \mu \mathrm{g} / \mathrm{m}^{3}$ & $\begin{array}{l}\text { December 14, } \\
2012\end{array}$ & $\begin{array}{l}\text { (United States Environmental } \\
\text { Protection Agency, 2012) }\end{array}$ \\
\hline $\begin{array}{l}\text { United States } \\
\text { (EPA) }\end{array}$ & $\begin{array}{l}\mathrm{PM}_{10} \\
\text { Annual }\end{array}$ & $50 \mu \mathrm{g} / \mathrm{m}^{3}$ & $\begin{array}{l}\text { January 1, } 1987 \\
\text { Removed in } 1995\end{array}$ & (Wolff \& Perry, 2010) \\
\hline $\begin{array}{l}\text { United States } \\
\text { (EPA) }\end{array}$ & $\begin{array}{l}\mathrm{PM}_{10} \\
24 \text { hour }\end{array}$ & $150 \mu \mathrm{g} / \mathrm{m}^{3}$ & January 1,1987 & (Wolff \& Perry, 2010) \\
\hline $\begin{array}{l}\text { Environment } \\
\text { Canada (CAAQS) }\end{array}$ & $\begin{array}{l}\mathrm{PM}_{2.5} \\
\text { Annual }\end{array}$ & $\begin{array}{l}10 \mu \mathrm{g} / \mathrm{m}^{3} \\
8.8 \mu \mathrm{g} / \mathrm{m}^{3}\end{array}$ & $\begin{array}{l}\text { January } 1,2015 \\
\text { January } 1,2020\end{array}$ & (Environment Canada, 2013) \\
\hline $\begin{array}{l}\text { Environment } \\
\text { Canada (CAAQS) }\end{array}$ & $\begin{array}{l}\mathrm{PM}_{2.5} \\
24 \text { hour }\end{array}$ & $\begin{array}{l}28 \mu \mathrm{g} / \mathrm{m}^{3} \\
27 \mu \mathrm{g} / \mathrm{m}^{3}\end{array}$ & $\begin{array}{l}\text { January } 1,2015 \\
\text { January } 1,2020\end{array}$ & (Environment Canada, 2013) \\
\hline $\begin{array}{l}\text { Ontario MOECC } \\
\text { (AAQCs) }\end{array}$ & $\begin{array}{l}\mathrm{PM}_{2.5} \\
24 \text { hour }\end{array}$ & $30 \mu \mathrm{g} / \mathrm{m}^{3}$ & & $\begin{array}{l}\text { (Ministry of the } \\
\text { Environment, 2012) }\end{array}$ \\
\hline $\begin{array}{l}\text { Ontario MOECC } \\
\text { (AAQCs) }\end{array}$ & $\begin{array}{l}\text { Single facility max } \\
\text { emission of } \mathrm{PM}_{2.5} \\
24 \text { hour }\end{array}$ & $25 \mu \mathrm{g} / \mathrm{m}^{3}$ & & $\begin{array}{l}\text { (Ministry of the } \\
\text { Environment, 2012) }\end{array}$ \\
\hline
\end{tabular}


It should be noted that while the CAAQS limit of $\mathrm{PM}_{2.5}$ are more stringent then the National Ambient Air Quality Standards (NAAQS) in the United States, CAAQS objectives are voluntary while the NAAQS can penalize states under the American Clean Air Act (Environment Canada, 2013).

Given the potential for PM to travel over long distances, the problem spans national boundaries. In 1979 a Long-range Transboundary Air Pollution (LRTAP) convention was established by the United Nations (United Nation Economic Commission for Europe, 2014) . In 1991 a U.S.- Canada Air Quality Agreement was established with a focus on acid rain, to be revised to incorporate PM (Environment Canada, 2012).

It is understood that the smaller the particulate, the great chance it has at reaching the lower part of the lung and even pass through the cell blood membrane. As regulations are in mass, larger particles are able to tip the balance offsetting the number of smaller particles which may be present. With many studies investigating concentrations of UFP, interest has been raised to consider the count of particles to better represent the severity of smaller particles preset in the air.

\section{Bicycle Air Monitoring}

This project was developed to manage and analysis the VGI collected from the Bicycle Air Monitoring (BAM) program. The BAM program was born out of a need to help better understand the ground-level exposure of individuals to PM in Hamilton Ontario. This is the first bicycle air quality monitoring program of its kind in Canada. Launched in July 28th, 2014 volunteer cyclists are equipped with an air quality sensor used to measure PM during their ride. 
A GPS device is also barrowed which tracks their location to be used to pinpoint where PM measurements are taken. The collected data is then downloaded from the device for analysis.

\subsection{0rganizer}

The coordinating organization for the BAM program is Environment Hamilton (EH). EH is a nonprofit organization which was incorporated in 2001 (Environment Hamilton, 2014). The seed funds which were used to establish $\mathrm{EH}$ were secured from a fine-sharing provision in the federal Fisheries Act paid by the city of Hamilton for allowing a landfill to leak toxic contaminates into Red Hill Creek. Since its establishment, dozens of environmental initiatives have been undertaken. Lynda Lukasik helped create EH and assisted as part of the charges laid against the City of Hamilton with support from Sierra Legal Defense Fund and the Environmental Bureau of Investigation. She is the main point of contact for the BAM project in Hamilton and works as its Executive Director.

A Toronto based study using the same sensors to measure PM is also being conducted in collaboration with EH by the Toronto Environmental Alliance (TEA), under the project title Initiative for Healthy Air \& Local Economies (INHALE). A partnership began between the two organizations in 2009 with a Good Neighbour Campaign (GNC) (Crawford, 2012). The GNC was geared towards opening lines of communication between industry and local residence, with a focus on reducing problem emissions from the air (Crawford, 2012). TEA will be using the BAM Map Engine framework to share the results for their neighbourhood specific study. The BAM program has four (4) objects established by EH.

1. Educate cyclists of air quality in Hamilton

2. Highlight areas in Hamilton with increased levels of PM using an online map

3. Investigate areas identified with increased levels of PM to understand root causes 
4. Facilitate efforts to avoid exposure to increased levels of PM

\subsection{Project Origin}

The BAM program facilitated by EH is modeled after one conducted by the Pittsburgh Group Against Smog and Pollution (GASP). The GASP Bicycle Air Monitoring (BAM) program uses 4 mobile air quality monitors lent to volunteer cyclists who sign-up online and borrow an air quality sensor for an average of 2 weeks. The collected data is compiled at monthly intervals and shared with the public using an online map. The GASP BAM interactive map launched January 16, 2014. GASP has been very helpful in assisting EH with their BAM program. 


\subsection{Volunteered Geographic Information}

The BAM Map Engine was developed to managed data collected by volunteers during their bike rides. The concept of recruiting members of the public to collect data with location information is known as Volunteered Geographic Information (VGI) (Goodchild, 2007). Georeferencing or geolocation is when information is plotted on a map at its real-world location. One of the main benefits of VGI is the reduced cost compared to traditional mapping techniques, allowing for a much richer picture then afforded by government and private agencies. This is also known as crowdsourcing, as many individuals are brought together to collectively work on project. There are many examples of successful VGI initiatives, with one of the largest being eBird (Klinkenberg, 2015), a bird reporting service developed by Cornell Lab of Ornithology and National Audubon Society. Another hugely successful VGI initiative is OpenStreetMap (OSM). OSM is a community generated map fed by local knowledge, with the data generated made freely available to the public (OpenStreetMap, 2015).

The act of collecting data performed by these "citizen scientists" offers many benefits over traditional agency data collection techniques. The ability to collect a large dataset is made possible as volunteers are motivated by the experience over monetary compensation (Johnson, et al., 2014). As well, the increase in scientific literacy of participants not only informs them of pressing issues in their local community but also those in their network (Johnson, et al., 2014). The main disadvantage presented with citizen generated data is its reliability. Careful data collect techniques is one way to address data quality concerns (Comber, et al., 2013) and luckily for the BAM project the simplicity of the data collection methods employed makes the process almost fool-proof. 


\subsection{Equipment}

The concept of humans as sensors has been afforded by recent advancements in technology and its availability (Goodchild, 2007). The main tool used to collect PM data is a battery powered laser particle counter able to detect two ranges of particle size and store the results on an internal memory chip. Fourteen personal air quality units have been purchased by EH through funds raised primarily from Hamilton Public Health. The specific unit model is the Dylos Logger v 1.6.0.0 DC1700 v 2.05s (Dylos Corporation, 2014). These air quality loggers have been modified to allow samples to be collected every 10 seconds, instead of the default 1 minute. The Dylos logger offers 6 hours of continuous use, with a storage of 27 hours worth of samples (Dylos Corporation, 2014). The Dylos unit is strapped to the handlebars of the volunteers bike using 4 Velcro straps for easy removal between rides.

Georeferencing PM sample values is made possible by running a portable Global Positioning System (GPS) simultaneously during sample collection. Using the Columbus V990 data logger, locations are able to be pinpointed with an accuracy of up to $1.5 \mathrm{~m}$ using an "Enhanced Positioning System" (Columbus GPS, 2011). The battery life of the Columbus V990 is 24 hours in track log mode and can hold 50 million waypoints on a $4 \mathrm{~Gb}$ microSD card (Columbus GPS, 2011). GPS coordinates are collected in EPSG: 4326 projection, with a location update every second. The unit is able to stores points collected for over 1.5 years continuously. The data logger is also equipped with voice recording capability. Volunteers are instructed to identify a sporadic increase in adverse air quality when encountered using the voice record feature to help identify the source. The GPS unit can be hung from a lanyard or placed in ones pocket for quick retrieval. 


\subsection{Methods}

In this project, a Web-based Geographic Information System (GIS) was developed to assist with the management of the air quality data being collected. The system supports administration and public viewing of the data. The administration side allows air quality measurements, GPS locations, and voice recordings to be uploaded simultaneously and stored online. The timestamp field, associated with GPS locations and PM sample records are used to join the two data files (recognizing that six (6) air samples are taken every minute). Audio file names are referenced in the GPS logs, allowing for its association. For each air sample, a location on the map is plotted. Every data upload is considered a set, generating a chart showing temporal samples relative to the closest fixed air monitor levels. Each volunteer has an online account on the administration side of the site, enabling them to log-in and view the data collected during their rides. Users can also upload the samples they collect themselves with additional training. For a visual representation of the components which were brought together to form the BAM Map Engine see Figure 2 Bicycle Air Monitoring Map Engine Overview.

On the public viewing side, for speedy retrieval of samples, a clustering algorithm is used to group near samples together. When a cluster is clicked, a chart displaying all samples collected for that specific cluster are displayed in an information window. Panning the interactive map reveals clusters beyond the confines of the current map bounds and zooming-in shows smaller clusters stored within larger ones. A direction service is provided allowing visitors to specify a start and end locations which returns multiple cycling routes along with the estimated cumulative exposure of $\mathrm{PM}_{2.5}$ for each route. 


\section{Bicycle Air Monitoring}

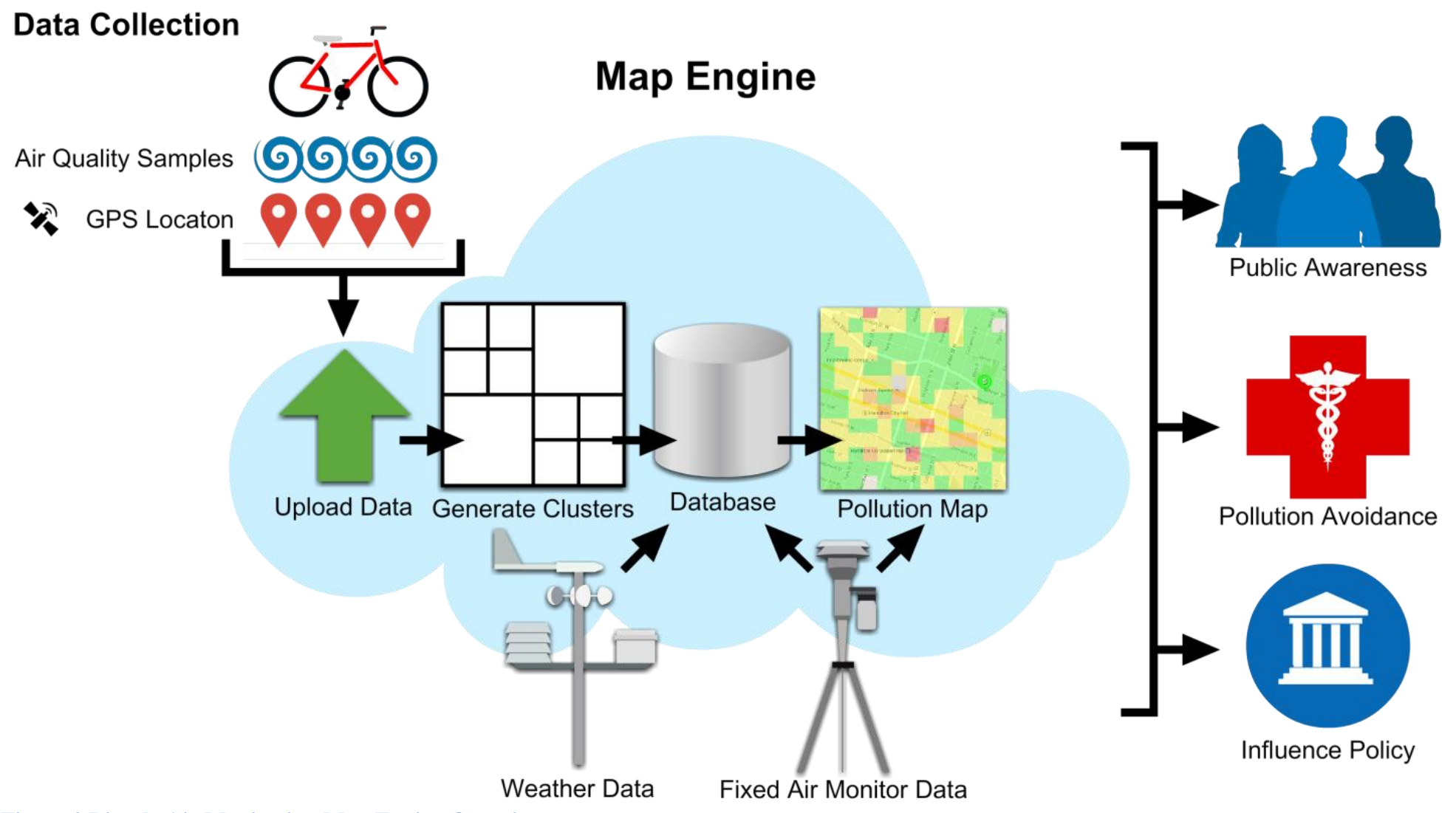

Figure 2 Bicycle Air Monitoring Map Engine Overview 


\subsection{Dylos Count to Mass Correlation}

To determine whether the air quality monitoring equipment provides suitable readings compared to the fixed stations, a direct comparison was done after a review of investigations by others. The main difficulty in the comparison is that the Dylos air quality monitor measures in counts per cubic foot and the fixed stations follows the regulation units which are in mass. It should be noted that the Dylos air quality unit is a relatively inexpensive air quality monitor compared to other devices used, at $\$ 425$ USD which raises concerns of measurement trustworthiness.

Few studies have been done to assess the effectiveness of the Dylos air quality monitoring unit. One study compared the Dylos DC1700 against the SidePak AM510 personal air quality monitor (which shows readings in mass) (worth $\$ 4,100$ USD) and established an equation to convert the count of indoor readings to mass in $\mu \mathrm{m} / \mathrm{m}^{3}$ with an $\mathrm{R}^{2}$ of 0.90 (Semple, Apsley, \& MacCalman, 2012). Experiments have also been done in Beijing comparing the Dylos 1100 to a profession grade stationary air quality monitor, the Beta Attenuation Monitor (AQICN, 2013). By simply graphing the Dylos $>0.5$ reading against the stationary $\mathrm{PM}_{2.5}$, comparable fluctuations are presented.

To assess whether a conversion can be performed an equation has been derived by comparing values measured from a fixed air quality monitor against the mobile monitoring unit. Working with the Air Monitoring and Transboundary Air Sciences Section as part of the Ontario Ministry of the Environment \& Climate Change, a Dylos air quality monitor was placed next to the air inlet of a Thermo Scientific 5030 SHARP located at 125 Resources Road on the west-end of Toronto. See Figure 3 Dylos DC1700 Mounted near air inlet of 5030 SHARP at 125 
Resources Rd. Toronto. The results of the correlation can be seen in Correlation Analysis section of this report.

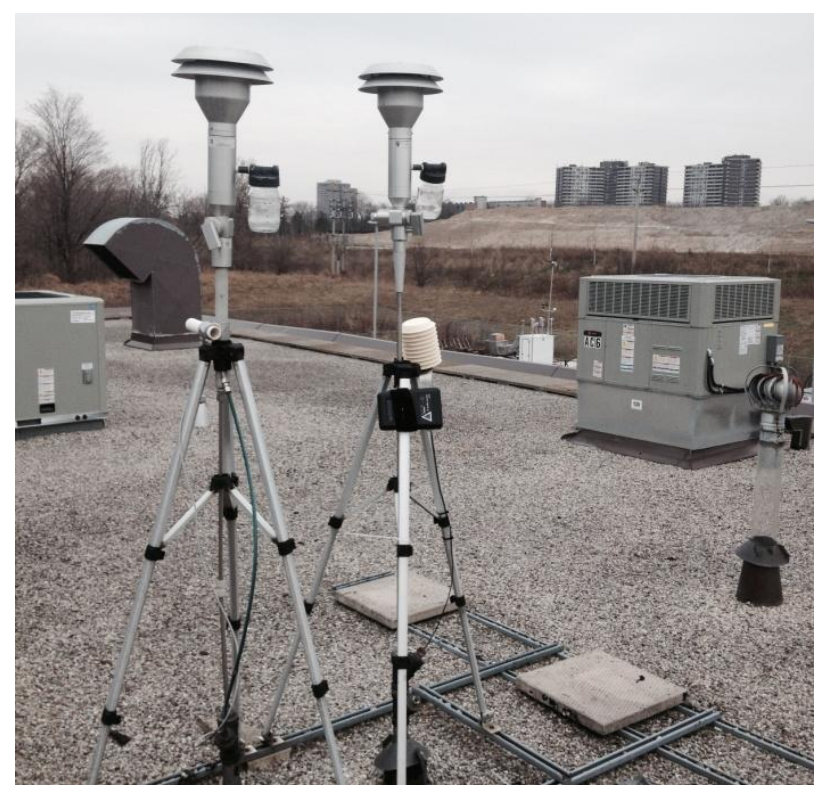

Figure 3 Dylos DC1700 Mounted near air inlet of 5030 SHARP at 125 Resources Rd. Toronto

\section{Application Design}

\subsection{Web-based Application}

In Ontario, two fixed station air quality networks have online maps presenting their data to the public. Air Quality Ontario (http://www.airqualityontario.com) uses a composite value to represent ambient hourly air quality samples called the Air Quality Index (AQI) which can be visualized on a map. As well, the Hamilton Air Quality Monitoring Network (HAMN) (http://www.hamnair.ca) has 14 fixed air quality monitoring stations which publish hourly data online. Multiple pollutants are being monitored at each of the HAMN stations, although $\mathrm{PM}_{2.5}$ is not among them. Unlike the Air Quality Ontario interactive map, HAMN does not display concentration on the map, requiring users to navigate to another page for readings. Toronto does not have its own monitoring network, with the City of Toronto site referring to the Environment 
Canada Air Quality Health Index (AQHI) ratings which are not mapped. Perkin Elmer has a distributed network of fixed monitors, with a few being tested at the University of Toronto ( $\mathrm{U}$ of T). Each unit is equipped with $\mathrm{Wi}-\mathrm{Fi}$, transmitting multiple pollutant readings to an interactive map available to the public (http://elm.perkinelmer.com/map/\#/523). $\mathrm{U}$ of $\mathrm{T}$ has also been working to develop their own low cost sensors with 5 deployed across the Toronto area (http://airsensors.ca/).

As part of the BAM Map Engine objectives, a tool to facilitate selecting a clean air route for cyclists is sought. To date, several online bicycling trip planners have been developed for specific cities including Vancouver (http://www.cyclevancouver.ubc.ca), Los Angeles (http://opt.berkeley.edu/) and San Francisco (http://amarpai.com/bikemap). Each offers the ability to choose a bike-friendly route and some even offering air pollution avoidance. In Toronto an application called Ride the City was recently launched which factors in bike facilities when choosing a route (Ride the City, 2014). Three route options are available with Ride the City; direct, safe and safer; however, you can only choose to see one route at a time. Ride the City is focused on safety for its route selection criteria and does not directly consider air quality exposure.

Numerous studies have made mention of the potential benefits of having a web-based low exposure bicycling route service. A Vancouver study revealed that "information about cycling routes to the destination" was ranked within the top 15 motivating factors among regular and occasional cyclists (Sua, Winters, Nunes, \& Brauer, 2010). As well, the ability to have multiple route options is advantageous given the different comfort levels of cyclists with regard to vehicular traffic (Ehrgott, Wanga, Raith, \& Houtte, 2012). Features such as advisories for rush hour traffic would also be of benefit (Hertel, Hvidberg, Ketzel, Storm, \& Stausgaard, 2008). 


\subsection{Application Walkthrough}

The BAM Map Engine was developed with consideration of past studies and their mention of beneficial features, along with a review of existing web-maps showing air quality and bicycling routes. A walkthrough of the applications is as follows:

When visitors first enter the site they are presented with a prompt providing a welcome note with basic background information. Behind the prompt a satellite web-map is displayed showing Hamilton and Toronto, overlaid with semi-opaque cluster squares colour-coded based on an aggregate of all collected $\mathrm{PM}_{2.5}$ levels (compared to the mean $\mathrm{PM}_{2.5}$ during each sample period).

A legend on the top right is present, showing all possible cluster colours with a tooltip detailing the colour range values and meanings.

Air Quality Ontario fixed $\mathrm{PM}_{2.5}$ monitor readings are displayed on the map showing the hourly values measured, coloured coded based on the Air Quality Index cut-offs (Ministry of the Environment and Climate Change, 2010).

As the user zooms in (by double-clicking the map, rolling the mouse wheel or clicking the plus arrow button) the fidelity of the clusters increases revealing nested sample clusters within the larger ones. Each cluster is interactive (as indicated by the mouse icon changing to a pointer) and reveals an info window with all the samples collected at that location in chart form when clicked.

To quickly navigate to a specific neighbourhood (where $\mathrm{PM}_{2.5}$ has been measured), a cascading menu is available at the top left of the interface which zooms the map to a specific location bounds. A panel on the right side of the map (below the legend) presents the closest fixed $\mathrm{PM}_{2.5}$ monitor readings, offering a real-time view of the ambient $\mathrm{PM}_{2.5}$ levels. 
Other links available along the top of the interface show a volunteer sign-up page,

references, feedback and log-in form. The ability to search for cycling directions is at the top left. Figure 4 BAM Map Engine Interface. 


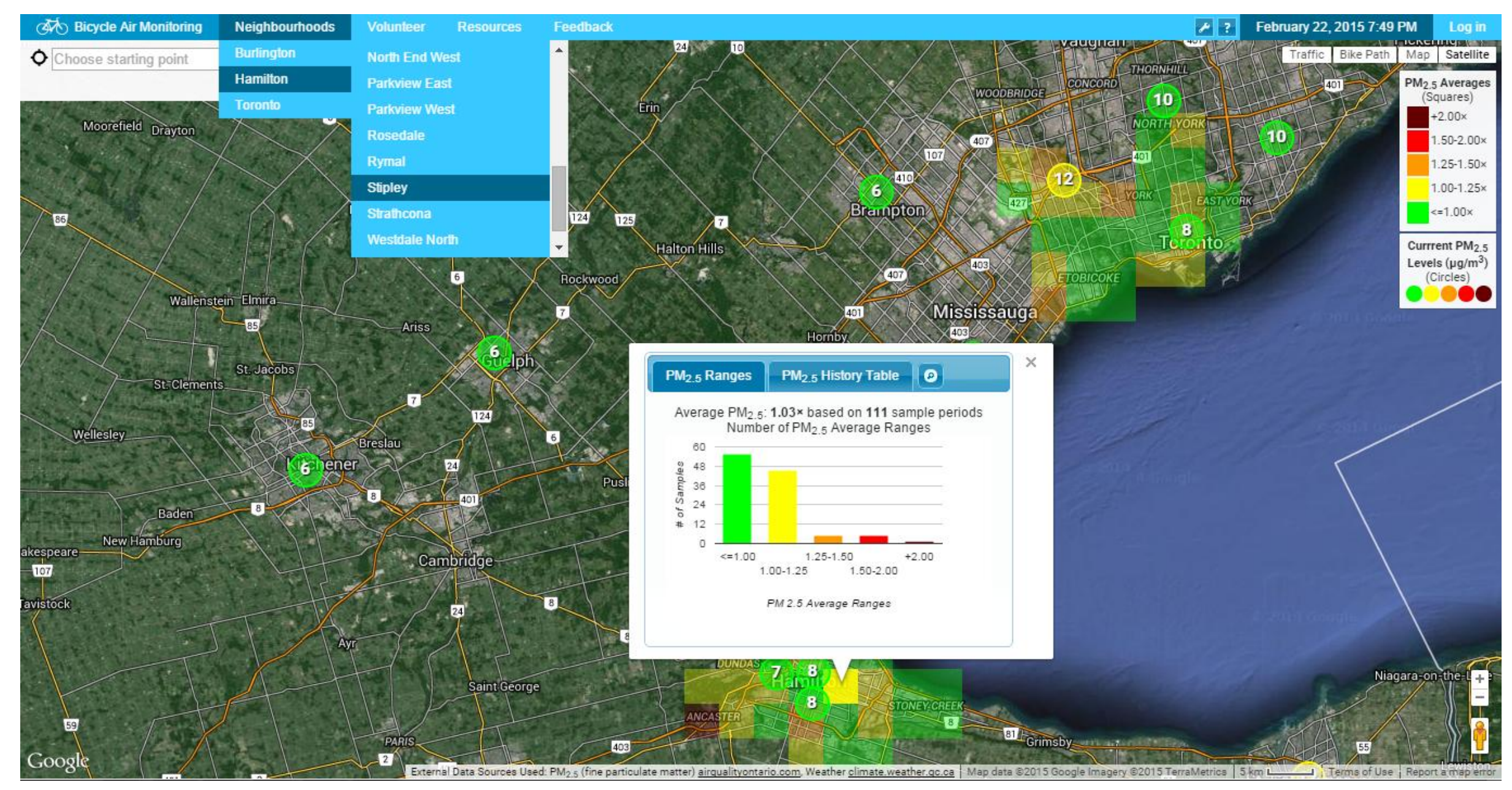

Figure 4 BAM Map Engine Interface 


\subsubsection{Direction Service}

In an effort to steer bicycling towards better air quality routes a direction service has been implemented as part of the BAM Map Engine. By utilizing the Google Direction Service API, the route results are used to present the estimated $\mathrm{PM}_{2.5}$ exposure along each route to quickly see which is the cleanest. Adjustments to the route will update the tallied $\mathrm{PM}_{2.5}$ estimates accordingly (e.g. dragging the route path, moving the start and end locations or submitting another direction request).

The direction service $\mathrm{PM}_{2.5}$ estimates are achieved as follows:

1. The process starts after a user enters a valid start and end location into the direction request form and clicks the submit button.

2. Two direction requests are made using Google's Direction Service API. One direction request looks at bicycling directions (with mode property set to BICYLING) and another request is made for driving directions (with mode property set to DRIVING). The bicycling direction request chooses routes which try to incorporate bicycling facilities and the option for alternative routes is set to true (up to two alternative bicycling routes are displayed). The driving direction does not consider bike lanes and chooses the most direct route. The driving direction request has been set to avoid highways.

3. The returned direction results are processed by first looking at the navigation path from the start of the route to the end. The navigation path associated with each route is segmented based upon the square clusters it passes through and the length of the line within each cluster.

4. All the clusters a route passes through are analyzed, looking to see if there are any PM samples collected within. 
5. A constant speed of $15 \mathrm{~km} / \mathrm{h}$ is assumed along the route and the duration within each cluster is determined by multiplying the speed by the path length within the cluster. This duration is multiplied by the average measured cluster $\mathrm{PM}_{2.5}$ level to estimate the amount $\mathrm{PM}_{2.5}$ along the route.

A value higher than 1 for $\mathrm{PM}_{2.5}$ along the route (Avg $P M_{2.5}$ column heading), means the $\mathrm{PM}_{2.5}$ along this route is above the average (established during historical samples collected within the same clusters intersecting the route, compared to all the samples collected during each of the previous sample periods). As this value is based on the available data, a confidence percent is generated by comparing the length of the route which passes through areas with data, against the entire route length. See Figure 5 BAM Map Engine Direction Interface 


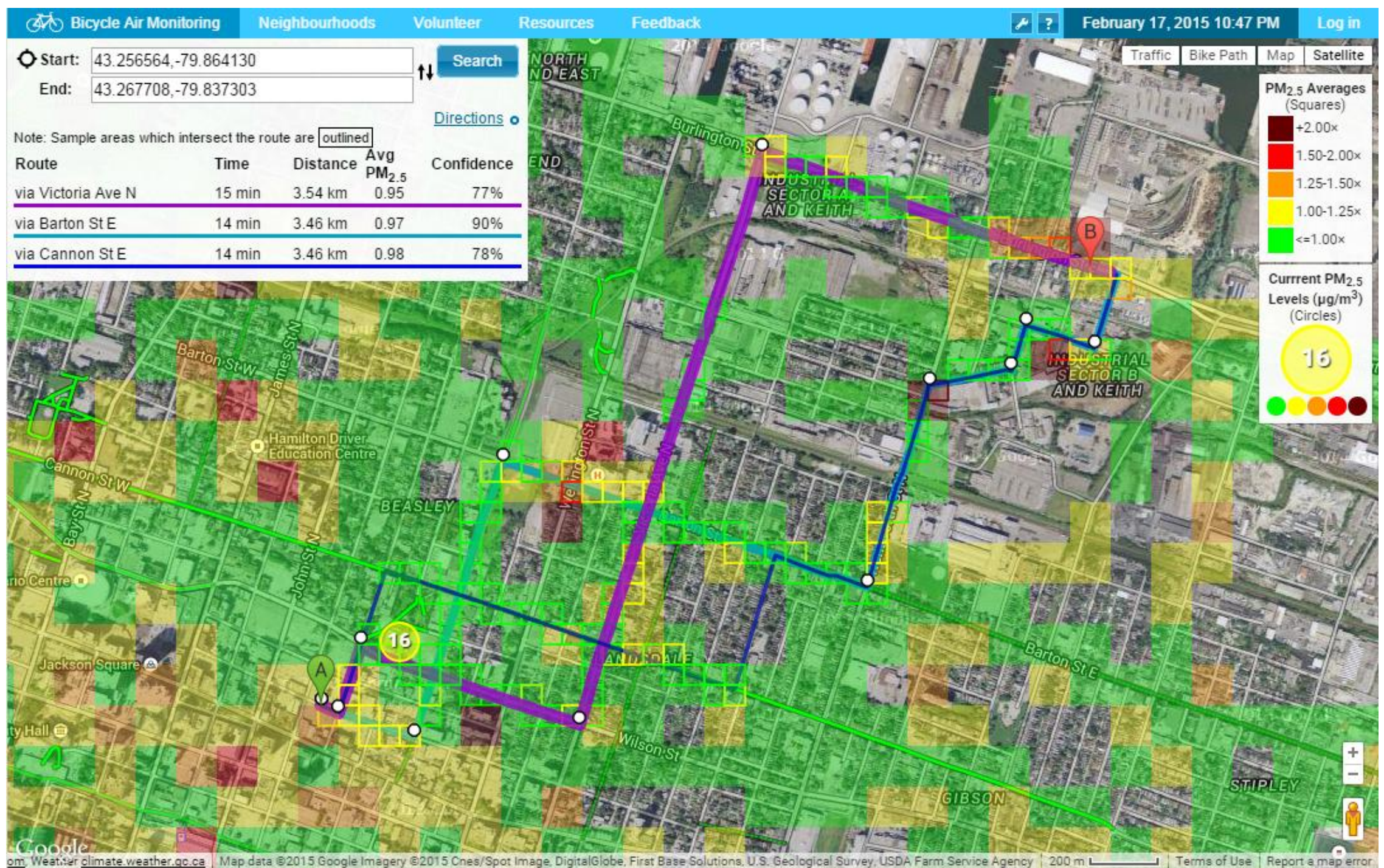

om Weattier climate weather.90.ca, Mapdata 62015 Google Imag 


\subsection{Data Management}

The developed BAM Map Engine organizes volunteer data using a relational database and dynamically generated folder structure (for audio files). The administrative component of the application allows uploading, retrieving, modifying and deleting of data. To upload data, a user must first be logged-in as either an Administrator or Member. There are 3 membership types in total, which are Administrator, Member and Volunteer; each offering a different level of capabilities See Table 2 Membership Capabilities.

Table 2 Membership Capabilities

\begin{tabular}{|ll|lll|}
\hline Membership & $\begin{array}{l}\text { Membership } \\
\text { Creation }\end{array}$ & $\begin{array}{l}\text { Membership } \\
\text { Editing }\end{array}$ & Upload Data & View Data \\
\hline Administrator & Yes & All users & All users & All users \\
\hline Member & No & Only self & Only self & Only self \\
\hline Volunteer & No & Only self & None & Only self \\
\hline
\end{tabular}

\subsubsection{Publishing Data from Devices}

\subsubsection{Downloading Data from Devices}

The first steps towards publishing the PM data involves downloading the data collected from both Air Quality Monitor and GPS device.

\subsection{Dylos Data Download}

The Dylos monitor requires a 9-pin Serial Cable to USB (not packaged with the device) along with a driver to create a virtual COM port. Note: The driver is associated with a specific USB port on the computer, so the same port should be used each time. To download data from the monitor, propriety software called DylosLogger V1.6 is to be installed and run after the unit has been plugged into the computer (Dylos Corporation, 2012). The Download History button 
will be active from the toolbar of the software. Once the Download History button has been clicked, the Download History Window opens and after clicking the Download button, line-byline data is read-out in the text area. When all the data has been transmitted to the interface, the Create Log button highlights. Clicking Create Log saves the data as a single .txt file to the location indicated by the address bar, see Figure 6 DylosLogger 1.6 Download History Window.

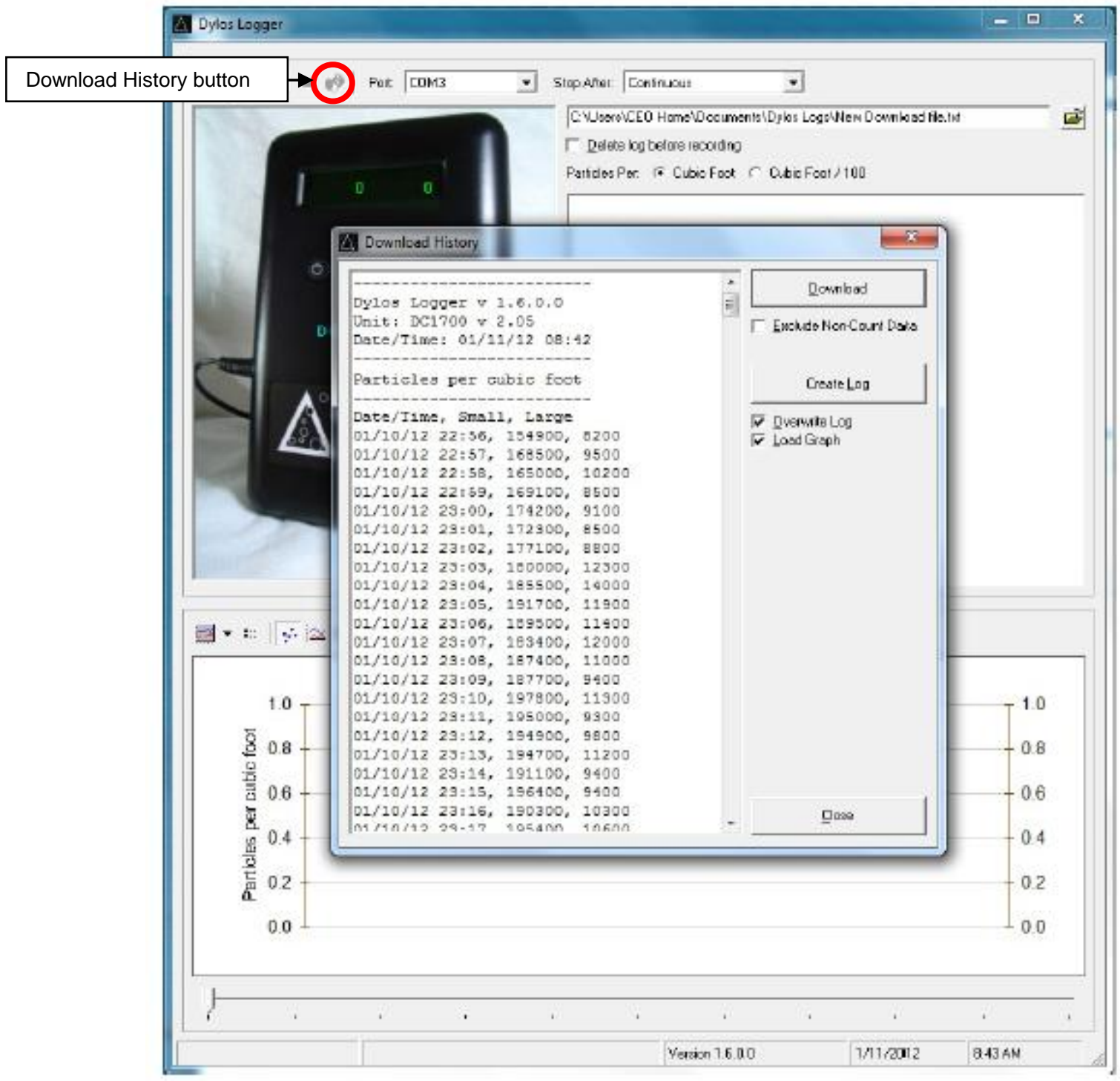

Figure 6 DylosLogger 1.6 Download History Window 
Once the data has been successfully downloaded, it can be removed from the device by clicking the Mode button several times on the front of the device, until the LCD display reads "Clear History" (pressing select when prompted clears the history).

\subsection{GPS Data Download}

The GPS data can be easily downloaded from the device by removing the microSD card and using an adaptor to connect the device to a USB port on the computer. Drivers for the USB adaptor should automatically install (or can be retrieved from the manufacturer of the adaptor). The data files stored on the device are comma separated variables (CSV) and wave audio files (WAV). A separate CSV file is created every time the device is turned on and a new audio file is created every time the record button is released. Both file types can be cut and pasted to the local computer hard drive.

Note: It is recommended to keep data files organized on the local computer using a single folder for each sample set containing the 3 file types generated by the devices (.txt, .csv, and .wav).

\subsubsection{Uploading Data}

Utilizing web-based technologies, the only system requirements to upload the data to the BAM Map Engine include a modern browser and internet access. HTML5 functionality affords the ability to upload multiple files of different types by simply dragging them into a predefined area on the webpage. The Upload Files button becomes visible after logging-in as either an Administrator or Member. Uploading the files also can be done by clicking the Upload Files button and selecting all the files from the local hard drive for a specific sample set, then clicking the Open button. The upload process begins automatically (so make sure all files are uploaded together). After the files are uploaded, two repositories are created in memory, one for sample locations and the other for sample measurements. Audio files are also stored in memory using 
base64 format and later saved to a folder on the server. Once all the files have been parsed, each sample is looped over, checking them against the location repository to see if any timestamps matchup. Since the Dylos measurements do not have seconds as part of their timestamp, the seconds are artificially determined based on the number of occurrences of the same time. The GPS unit collects locations every second after it has locked onto a satellite signal. Multiple GPS locations are recorded within the 10 second sample interval of the Dylos monitoring unit and as such, the middle location (of all the possible 10 GPA location records) is selected to be associated with the sample. After all the associations have been made, a prompt is presented to the user allowing them to choose whether the units are in Daylight Savings Time (DST) or Standard Time (ST). This prompt also includes a dropdown allowing the Dylos unit number to be entered and displays the number of samples able to be geolocated. Clicking Submit continues the upload process.

The samples are then broken down into sample periods which is considered a continuous trip with no breaks lasting more than an hour. Each sample period has an average generated from the containing sample values. The average is based on the small particle count $(>.5 \mu \mathrm{m})$ minus the large particle count $(>2.5 \mu \mathrm{m})$ to produce a count between $0.5-2.5 \mu \mathrm{m}$ to be referred to as $\mathrm{PM}_{2.5}$. Each sample $\mathrm{PM}_{2.5}$ value in the sample period is checked against the $\mathrm{PM}_{2.5}$ average to determine its normalized $\mathrm{PM}_{2.5}$ value. Several processes are then performed for each sample:

1. A containing cluster is found for each of the samples at each of the zoom levels (7 levels exist based on grid sizes, the smallest one being $27 \times 27 \mathrm{~m}$ ). If more than one sample (within a sample set) falls in the same cluster, a grouped sample is created with a value equality weighted between those clusters. Association for each of the cluster levels are 
stored with unique samples and sample groups. Sample groups also store a reference to each of the contributing samples, allowing for later data dissemination.

2. The closest fixed MOECC air quality monitor is detected and the historical $\mathrm{PM}_{2.5}$ data is downloaded and associated with the sample.

3. The closest weather station is also detected and the historical values for temperature, wind direction, wind speed and humidly are downloaded from Environment Canada and associated with the sample.

4. Every 50th sample location is geocoded using the Google places API to find the closest, neighbourhood and boundary. The neighbourhood names are used for constructing a navigation menu for quickly accessing locations with data.

Once all processes are complete, the associated samples are saved to the database and visualized on the map. A cheery audible is built into the system which alerts the user when the upload is complete. Alternatively, if an error is experienced (such as the case when a duplicate sample set exists), a drab audible is played. The newly added data allows notes to be added to each sample in text form, as well, a dropdown with predefined flags can be selected to provide an enhanced depth of knowledge and help better understand the source of sample measurements, see Figure 7 Sample Details Info Window. 


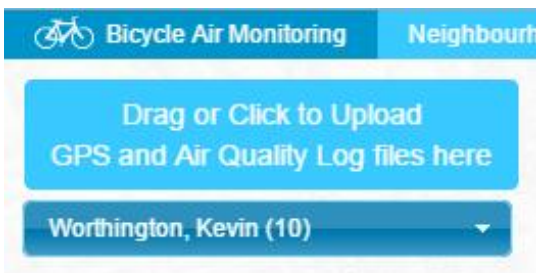

\section{Sample Set: Mon Sep 082014 而}

Start Time: Tue Sep 092014 17:23

End Time: Tue Sep $09201421: 41$

Highest $\mathrm{PM}_{2.5}: \quad 4.64>.5 \mu / 100{\mathrm{n} / \mathrm{ft}^{3}}^{3}$

Lowest PM $2.5: \quad \underline{0.56>.5 \mu / 100 . \mathrm{n}^{-1} t^{3}}$

Max Speed: $48 \mathrm{~km} / \mathrm{h}$

Average Speed: $16.58 \mathrm{~km} / \mathrm{h}$

Choose starting point

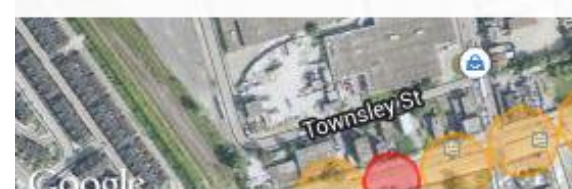

\section{in}

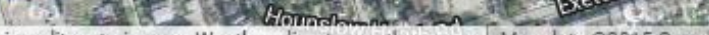

\section{Data/Time Tue Sep 09 2014 6:30 PM $\times$ Speed $\quad 0$ km \\ $\mathrm{PM}_{10}$ Count $147100 . \mathrm{n} / \mathrm{ft}^{3}$ \\ $\mathrm{PM}_{2.5}$ Count $1587100 . \mathrm{n} / \mathrm{ft}^{3}$ \\ $A Q P M_{2.5} \quad 5 \quad \mu g / m^{3}$ \\ comment \\ 5 r

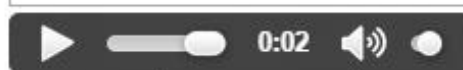

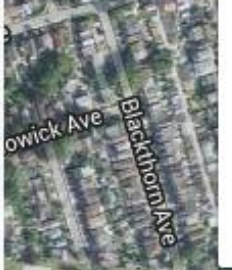

Flag

Choose Flag $\mathbf{v}$

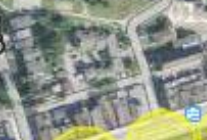

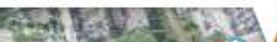

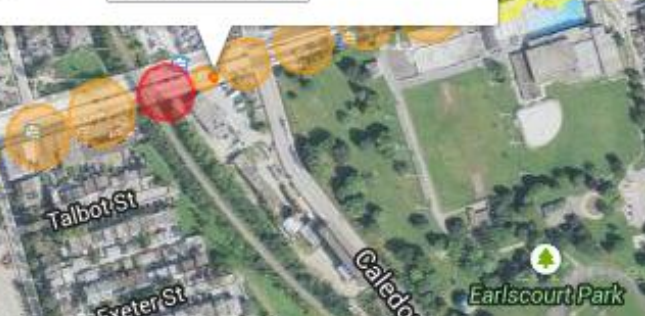

A ? February 17, 2015 10:55 PM

Kevin Worthington of

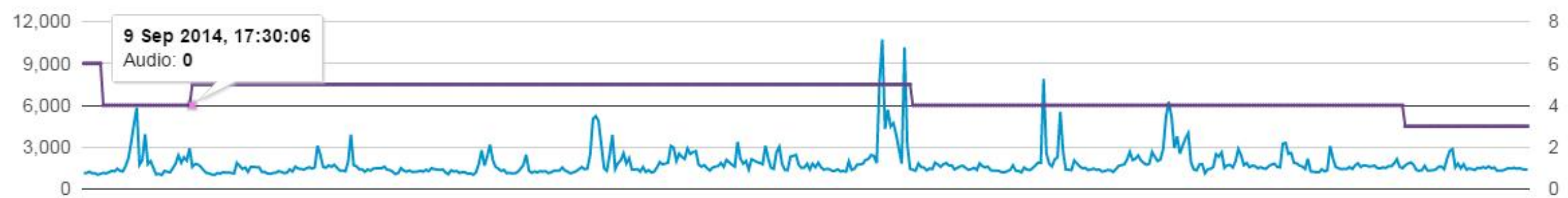

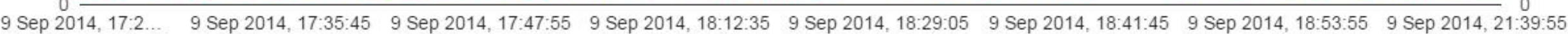

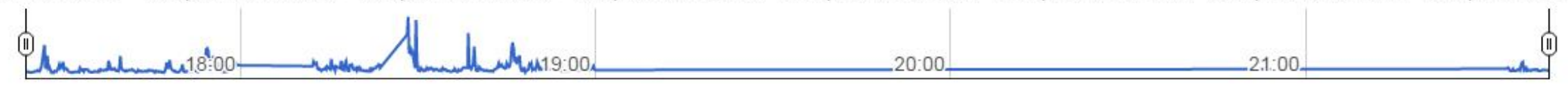

Figure 7 Sample Details Info Window 


\subsection{Technologies Used}

The underlying technologies used to construct the BAM Map Engine include Google Maps and the LAMP open-source software bundle (Linux, Apache, MySQL and PHP). Google Maps was chosen over other web-based mapping technologies (BING, OpenStreetMaps) primarily for its bicycling direction service. The limitation of choosing Google Map involves its licensing agreements, but they are not overly restrictive for our purposes. The LAMP software bundle is a cost effective server option compared to alternatives such as Microsoft Application Server.

\subsection{Clustering Samples}

In consideration of the scalability to the BAM Map Engine, a server-side clustering algorithm was needed to improve download performance by precompiling information. Three clustering methods were investigated which include proximity, hexagonal and grid. The proximity-based clustering method allowed for low overhead but did not scale well, as the more clusters created, the more records must be checked against to determine whether they are within the map bounds. There is also the issue of cluster overlap, as sample records may fall just beyond the threshold of an existing cluster requiring the spawning of a new one (which may contain samples from the overlapped cluster). A hexagon clustering system allows a circle like shape to be used but since hexagons can be positioned uniformly together, there is no overlap. Hexagonal overlap did however become visible, due to the Mercator projection as clusters neared poles. The grid-based clustering approach did not suffer from overlap, as squares fit uniformly together. It also allowed for scalability, since the clusters present within the map's bounds can be easily determined on the client side. As such, the grid-based clustering approach was chosen. 


\subsection{Programming Languages}

The following programming languages and their purposes have been utilized in the construction of the BAM Map Engine:

\begin{tabular}{|ll|}
\hline Language & Purpose \\
\hline HTML & Interface layout \\
\hline JavaScript & Interactivity \\
\hline CSS & Styling \\
\hline jQuery & Enhanced interactivity \\
\hline AJAX & Asynchronous data loading \\
\hline PHP & $\begin{array}{l}\text { Database connectivity } \\
\text { Loading and parsing external MOE pages }\end{array}$ \\
\hline
\end{tabular}

Each language has a specific usage and thus are kept mostly separate from each other, being loaded in as needed.

\subsection{Database Design}

Storage of the data associated with the BAM Map Engine is primarily done using a MySQL database. The table names are self explanatory in regards to their purpose, though a few notes are worth mentioning. Nineteen tables are used in total. See Figure 8 Database Design for a complete list of database tables and fields.

Membership types are defined by the type field, with type 2 for Administrators, type 1 for Members and type 0 for volunteers.

All samples are associated with a specific sample set and sample period, using table named as such. The member_id and collection data are used to prevent duplicate samples from being uploaded. Group samples are identified by having a is_group flag of 1 .

Seven tables are solely for the purpose of precompiling aggregated values for PM counts at different cluster levels (prefixed with a location followed by the length in meters). The 
location_sample tables is a many-to-many table allowing a direct link to specific sample records from each location cluster.

Three tables are used for storing neighbourhood information (province, city and neighbourhood). 


\section{Correlation Analysis}

As the Dylos air quality monitor measures PM in counts and the regulation limits are in mass, a comparison between the measurements was performed with a fixed air monitoring station operated by the MOECC at 125 Resources Road Toronto. The purpose of this exercise was to assess the reliability of the Dylos air quality measurements and the factors which affect its performance.

A Dylos DC1700 was deployed to the roof and mounted near the air inlet of the 5030 SHARP a $\mathrm{PM}_{2.5}$ monitor. Due to the lack of weather sealing of the Dylos unit, deployments were done on fair weather days, with one exception.

A total of 17,824 samples were collected over 10 days of data collection between December 5, 2014 and January 13, 2015. Each sample constituted 10 second averages of $\mathrm{PM}_{2.5}$ counts. This represented 49.5 hours of data which was compared to the minute data logged by the 5030 SHARP.

For accuracy of time comparison, it was attempted to synchronize the time of the Dylos unit to the SHARP 5030 unit terminal. Since it is not possible to adjust the seconds of the unit, the times were aligned with the Dylos unit 1 minute ahead, and pressing set when the terminal seconds zeroed-out. A check was done afterwards to see how synchronized the times were. After several attempts it was apparent that the Dylos seconds were not resetting so the difference in time was documented for adjustment during analysis.

See Appendix 1. Correlation Analysis Data Processing for the step steps used in processing the data. 
After joining all the data together 49.1 hours of 1 minute records were analyzed. As the 5030 SHARP unit records PM in the $<2.5$ microns range $\left(\mu \mathrm{g} / \mathrm{m}^{3}\right)$, the $>.5$ measurement (small) was subtracted from the $>2.5$ measurement (large) to produce a $<2.5$ and $>0.5 \mu \mathrm{m} / 100 . \mathrm{n} / \mathrm{ft}^{3}$ minute average to be referred to as $\mathrm{PM}_{2.5}$ count.

A linear trendline was established within a scatter plot chart which produced a $\mathrm{R}^{2}$ of 0.63 by directly comparing the $\mathrm{PM}_{2.5}$ count to the $\mathrm{PM}_{2.5}$ mass. See Equation 1 Linear Regression.

Equation 1 Linear Regression

$$
\text { Mass }=0.012 * \text { Count }+4.1038
$$

As $\mathrm{PM}_{2.5}$ incorporates a range of particles sizes starting at $<2.5 \mu \mathrm{m}$ the number of these particles (counts) and the weight of them (mass) is not likely to lineup do to the size variability. Figure 9 Dylos DC1700 to SHARP 5030 Correlation.

Note: The measurements from the 5030 SHARP terminal were in text format with a number followed by two underscores (\#\#_), this value was reformatted to exclude trailing underscores with equation $=\mathrm{LEFT}($ cell, $\mathrm{LEN}($ cell)-2) in Excel, then the resultant product was converted to a number by using "paste special" > "value" function in the right-click mouse menu. 


\section{Dylos DC 1700 to 5030 SHARP Correlation}

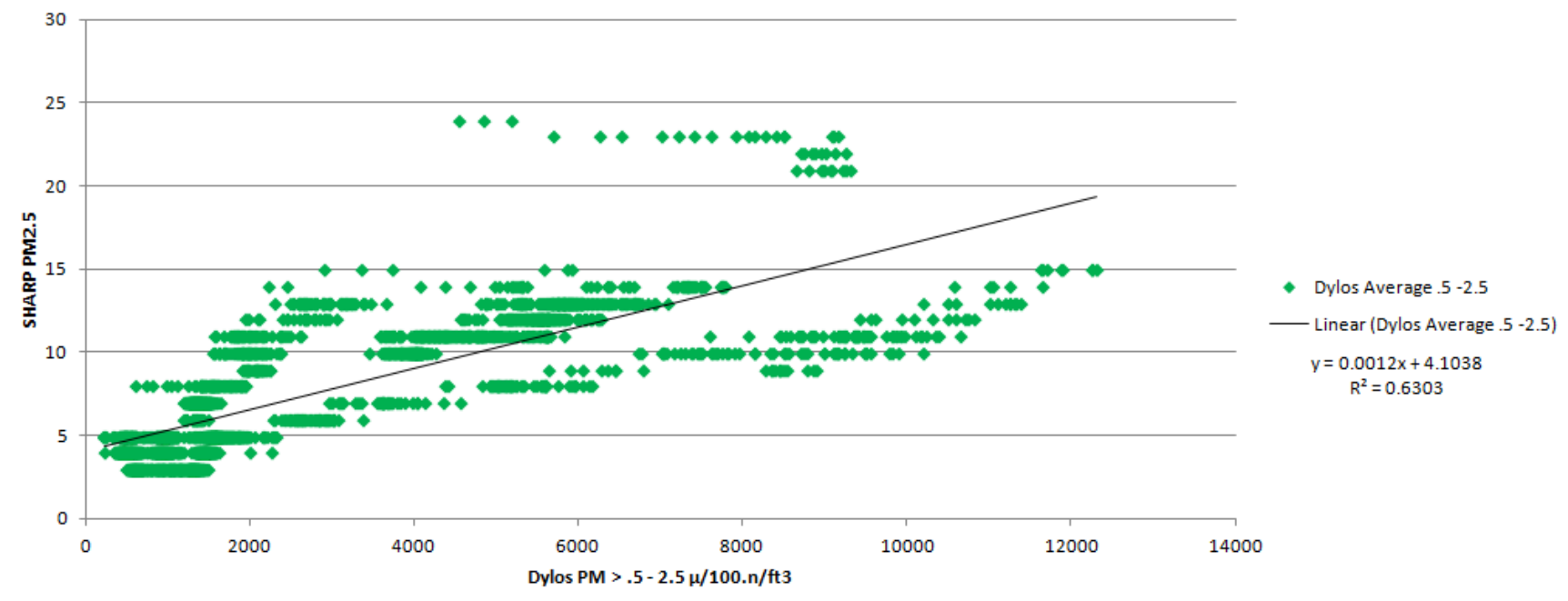

Figure 9 Dylos DC1700 to SHARP 5030 Correlation

While the correlation coefficient of 0.63 is considered moderate, there still exists a lot on variance. As the $5030 \mathrm{SHARP}$ is equipped with a moisture reduction system used to maintain the Relative Humidity (RH) (Thermo Scientific, 2015), its measurements are not as susceptible to the moisture in the air compared to the Dylos DC1700. To account for this variance, the Dylos measurements aligned with RH data collected nearby at 2 meteorological stations. To determine the best RH to use from the two stations, an average of the two stations wind direction was used as the determinate. If the average wind direction was $<45^{\circ}$ and $>315^{\circ}$ or $>135^{\circ}$ and $<225^{\circ}$ an average of the 2 RH's was used. If the average wind direction was $>=45^{\circ}$ and $<=135^{\circ}$ the East weather data was used. If the average wind direction was $>=225^{\circ}$ and $<=315^{\circ}$ the West weather data was used. See Figure 10 Dylos DC1700 PM Detection vs. SHARP 5030 PM \& Relative Humidity Over Time to see how the RH affects the Dylos readings. 


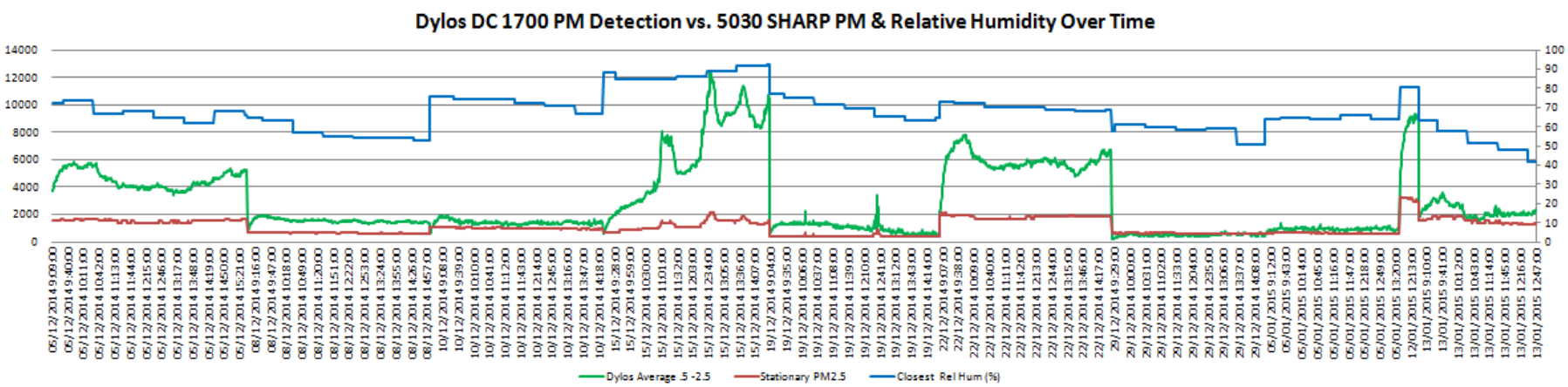

Figure 10 Dylos DC1700 PM Detection vs. SHARP 5030 PM \& Relative Humidity Over Time

By incorporating the $\mathrm{RH}$ as part of the curve-fitting analysis using multiple linear regression an $\mathrm{R}^{2}$ of 0.68 was achieved (up from 0.63). See Equation 2 Multiple Linear Regression Model. The $\mathrm{RH}$ (as a percent) is subtracted out to improve the correlation, signifying the exaggerating effect it presents.

Equation 2 Multiple Linear Regression Model

$$
\hat{y}=10.53+0.001492519 *(\text { Dylos } .5-2.5)-0.106365683 * \text { (Relative Humidity) }
$$

A chart of the 3 values can been seen in Figure 11 Dylos DC1700 PM Detection vs. 5030

SHARP PM \& Correlated Value.

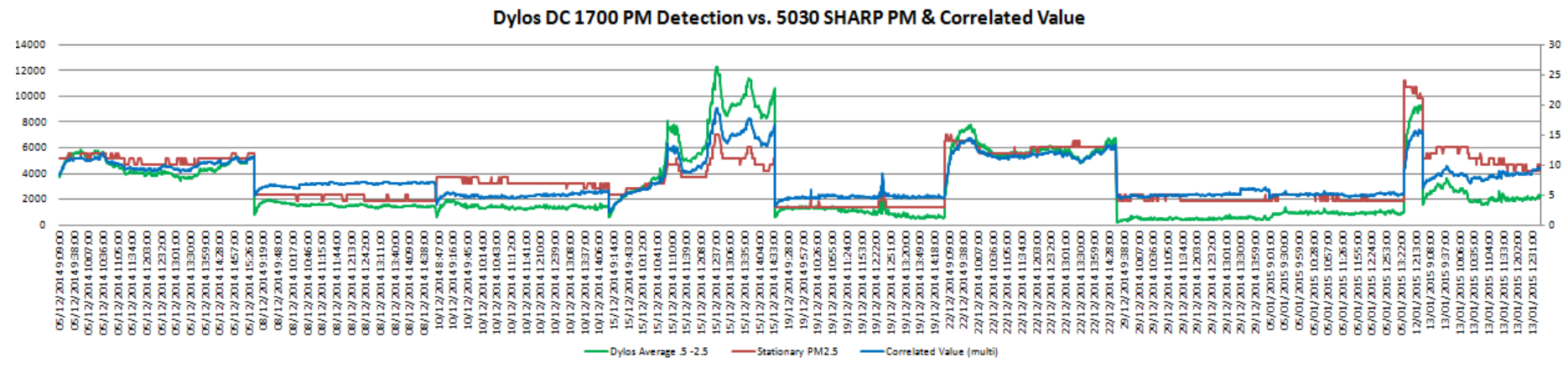

Figure 11 Dylos DC1700 PM Detection vs. 5030 SHARP PM \& Correlated Value 
Taking the correlation one step further and incorporating temperature which is a factor of $\mathrm{RH}$ using multiple linear regression, an $\mathrm{R}^{2}$ of 0.73 can be achieved using Equation 3 Multiple Linear Regression Model with RH and Temperature. This correlation demonstrates the sensitivity of the Dylos unit to the water vapor present in the air during higher $\mathrm{RH}$ conditions.

Equation 3 Multiple Linear Regression Model with RH and Temperature

$$
\begin{array}{r}
\hat{y}=7.877+0.001592653 *(\text { Dylos Average } .5-2.5)-0.0776864190773382 \\
*(\text { Relative Humidity })-0.178778770039289 *(\text { Temperature })
\end{array}
$$

From Equation 3 Multiple Linear Regression Model with RH and Temperature, the temperature has a negative correlation with the number of particles present which contradicts results found during the late summer and fall in Vancouver, British Columbia (Thai, McKendry, \& Brauer, 2008). See Figure 12 Coefficients of Determination Matrix for a graphical view of influencing variables in mass prediction.

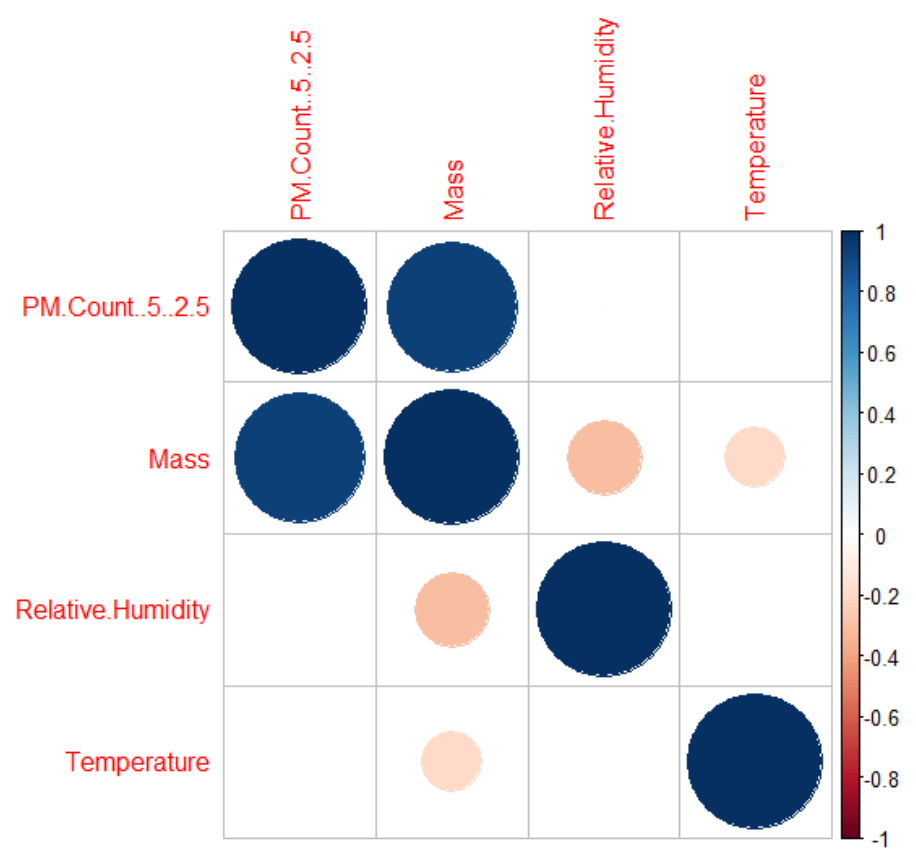

Figure 12 Coefficients of Determination Matrix 
Another factor present in the comparison of the measurements of two devices is the ability to detect darker particles. Petroleum based fuels, which produce darker particles, have been shown to absorb light affecting detection performance of the optical laser sensor used in a Dylos AQM (Dye, 2014). This would result in the underestimation of particle counts caused by vehicular emissions. As the 5030 SHARP model use beta-attenuation, PM mass is measured independent of its optical properties (Liberti, 1975).

\section{Preliminary Results and Discussion}

Although the Dylos unit is less sophisticated then more professional grade air quality monitoring units, it still offers the ability to measure elevated levels of PM. It should be recognized that on the one hand, the relative humidity may exaggerate results and on the other, darker particles may be underestimated. As well, multiple measurements should be used to confirm the existence of a $\mathrm{PM}_{2.5}$ hot or cold spot. With that said, preliminary results were investigated given the data available at time of writing (March 2015). There were 101,897 distributed samples available for this analysis with the majority within Hamilton Ontario.

To assist with identifying areas with chronically elevated levels $\mathrm{PM}_{2.5}$ basic filtering tools were developed. These tools allow only clusters with specific criteria to be displayed on the map and consist of the following:

- Cluster Sample Count: Enables the ability to display clusters with a minimum and maximum number of samples

- Cluster Average Value: Controls the display of clusters having a minimum and maximum average level of PM

- Cluster Size: Allows the size of clusters to be locked despite the map zoom 
For consistency of observations each location was assessed looking at major contributing factors relating to $\mathrm{PM}_{2.5}$ concentrations. It has been identified that $58 \%$ of $\mathrm{PM}_{2.5}$ is derived from residential and transportation sources (34\% and $24 \%$ respectively). As well, smelters of primary metals and other industrial process represent $33 \%$ of $\mathrm{PM}_{2.5}$ (12\% and $21 \%$ respectively) (MOECC, 2010). Plants have also been recognized as a sink for PM (McPherson, Nowak, \& Rowntree, 1994) with different species affording different effectiveness (Sæbø, et al., 2012). For this reason land-use criteria including residential, commercial, industrial, vegetation and perceived traffic volume, have been documented for each area of interest, which aligns with major $\mathrm{PM}_{2.5}$ contributing factors identified by Ross et al (Ross, Jerrett, Ito, Tempalski, \& Thurston, 2007).

A buffer of 227 meters (200+54/2 [for cluster radius]) from the clusters center has been programmed to appear when a cluster $i d$ is selected from the results table, as people living or working within $200 \mathrm{~m}$ of highways have higher exposure to $\mathrm{PM}_{2.5}$ then those living further away (American Lung Association, 2005) (Brugge, Durant, \& Rioux, 2007). As well, an exponential decrease from 17 to 150 meters downwind from the highway was reported for total particle concentrations (Brugge, Durant, \& Rioux, 2007). As the built environment can restrict air refresh, additional observations include these items. Investigations were undertaken using aerial photography, street view imagery and the Google traffic data layer. The inclusion of the OpenStreetMap (OSM) map layer was also made available for reference as it shows land use apportionment with more granularity than Google Maps. The OSM layer does however suffer from data inaccuracies (especially in the Resource and Industrial land use class around Toronto (Vaz \& Arsanjani, 2015)), though offers much promise in the future as it is continuously being updated. The first letter for each criteria (residential, commercial, industrial and vegetation) will 
be used along with a number from 0 - 10 representing the apportionment of the buffer area for each particular criterion, with 10 representing the entire buffer area. Traffic volume is described along with other notable items.

\subsection{High PM Locations}

To identify areas with chronically high levels of $\mathrm{PM}_{2.5}$ the adjustment controls were used set with the following parameters; Cluster Sample Count: Min: 8, Cluster Average Value: Min: 1.5, Cluster Size 1. As Toronto has yet to commence a full-fledged BAM project, the majority of the samples exist in Hamilton, where a total of 10 clusters were found from all the samples collected. These clusters were sorted based on their Average $\mathrm{PM}_{2.5}$ level (highest to lowest). The results uncovered from each of the locations can be found in Table 3 High PM2.5 Location Results

Table 3 High $\mathrm{PM}_{2.5}$ Location Results

\begin{tabular}{|c|c|c|c|c|c|c|c|c|c|c|}
\hline ID & Lat & Lng & Avg & $\begin{array}{c}\text { \# of } \\
\text { Samples } \\
\text { (Ranges) }\end{array}$ & $\begin{array}{c}\text { Nearest } \\
\text { Intersection }\end{array}$ & $\mathbf{R}$ & C & I & V & Observations \\
\hline 6127 & 43.256956 & -79.785118 & 2.74 & $\begin{aligned} & 9 \\
& (3<1.00) \\
(1 & 1.00-1.25) \\
( & 1.50-2.00) \\
( & (4>2.00)\end{aligned}$ & $\begin{array}{l}\text { Burlington } \\
\text { Street E and } \\
\text { Parkdale } \\
\text { Avenue N }\end{array}$ & 0 & 3 & 4 & 1 & $\begin{array}{l}\text { Beneath overpass ( } 4 \text { lanes below, } 4 \\
\text { lanes above) } \\
\text { Road surface is rough } \\
\text { Traffic Volume: High } \\
\text { Road Type: Collector, Arterial }\end{array}$ \\
\hline 7305 & 43.244953 & -79.770012 & 2.21 & $\begin{array}{c}9 \\
(8<1.00) \\
(1>2.00)\end{array}$ & $\begin{array}{c}\text { Rennie Street } \\
\text { and } \\
\text { Woodward } \\
\text { Avenue } \\
\text { Next to Red } \\
\text { Hill Valley } \\
\text { Parkway }\end{array}$ & 0 & 4 & 0 & 3 & $\begin{array}{l}\text { Majority of samples are below } \\
\text { average, with only } 1 \text { exceeding the } \\
\text { average by } 13.6 \text { times on Sun Oct } \\
26201410: 43 \mathrm{AM} \\
\text { Traffic Volume: High } \\
\text { Road Type: Local, Freeway }\end{array}$ \\
\hline 6126 & 43.256956 & -79.785805 & 2.11 & $\begin{aligned} & 8 \\
&(1<1.00) \\
&(21.00-1.25) \\
&(11.50-2.00) \\
&((4>2.00)\end{aligned}$ & $\begin{array}{l}\text { Burlington } \\
\text { Street E and } \\
\text { Parkdale } \\
\text { Avenue N }\end{array}$ & 0 & 3 & 5 & 1 & $\begin{array}{l}\text { Just West of ID } 6127 \\
\text { Majority of samples above average } \\
\text { Traffic Volume: High } \\
\text { Road Type: Collector, Arterial }\end{array}$ \\
\hline 6255 & 43.257956 & -79.777565 & 2.02 & $\begin{aligned} & 12 \\
& (6<1.00) \\
( & (21.00-1.25) \\
(1 & 1.50-2.00)\end{aligned}$ & $\begin{array}{l}\text { Windermere } \\
\text { Rd and } \\
\text { Parkdale }\end{array}$ & 2 & 0 & 5 & 2 & $\begin{array}{l}\text { East of cluster ID } 6127 \\
\text { South of aggregate storage area } \\
\text { Traffic Volume: High }\end{array}$ \\
\hline
\end{tabular}




\begin{tabular}{|c|c|c|c|c|c|c|c|c|c|c|}
\hline & & & & $(3>2.00)$ & Avenue $\mathrm{N}$ & & & & & Road Type: Collector, Arterial \\
\hline 6107 & 43.258456 & -79.805031 & 1.85 & $\begin{array}{c}8 \\
(4<1.00) \\
(11.00-1.25) \\
(3>2.00)\end{array}$ & $\begin{array}{l}\text { Burlington } \\
\text { Street E and } \\
\text { Kenilworth } \\
\text { Ave }\end{array}$ & 0 & 2 & 3 & 2 & $\begin{array}{l}\text { Beneath overpass ( } 4 \text { lanes below, } 4 \\
\text { lanes above) } \\
\text { Road surface is rough } \\
\text { Traffic Volume: High } \\
\text { Road Type: Collector, Arterial }\end{array}$ \\
\hline 7290 & 43.258956 & -79.775505 & 1.82 & $\begin{array}{c}9 \\
(5<1.00) \\
(11.00-1.25) \\
(3>2.00)\end{array}$ & $\begin{array}{l}\text { Windermere } \\
\text { Rd and } \\
\text { Woodward } \\
\text { Ave }\end{array}$ & 1 & 0 & 4 & 3 & $\begin{array}{l}\text { Just East of ID } 6255 \\
\text { Traffic Volume: High } \\
\text { Road Type: Collector, Arterial }\end{array}$ \\
\hline 6445 & 43.248954 & -79.804344 & 1.58 & $\begin{array}{c}\quad 12 \\
(4<1.00) \\
(1 \quad 1.00-1.25) \\
(3 \quad 1.25-1.50) \\
(21.50-2.00) \\
\quad(2>2.00)\end{array}$ & $\begin{array}{c}\text { Barton St E } \\
\text { and Harmony } \\
\text { Ave }\end{array}$ & 6 & 3 & 0 & 1 & $\begin{array}{l}4 \text { lane street } \\
\text { Traffic Volume: Medium } \\
\text { Road Type: Local, Collector }\end{array}$ \\
\hline 6835 & 43.267456 & -79.899101 & 1.57 & $\begin{array}{c}\quad 17 \\
(5<1.00) \\
(61.00-1.25) \\
(51.25-1.50) \\
\quad(1>2.00)\end{array}$ & $\begin{array}{l}\text { Norwood Rd } \\
\text { and } \\
\text { Longwood } \\
\text { Rd N }\end{array}$ & 5 & 0 & 0 & 3 & $\begin{array}{l}\text { East of large forest } \\
1 \text { sample measured at } 9.11 \text { times the } \\
\text { average } \\
\text { Traffic Volume: Low } \\
\text { Road Type: Local }\end{array}$ \\
\hline 5149 & 43.261456 & -79.855843 & 1.52 & $\begin{array}{c}\quad 14 \\
(5<1.00) \\
(41.00-1.25) \\
(31.20-2.00) \\
\quad(2>2.00)\end{array}$ & $\begin{array}{l}\text { Barton St E } \\
\text { and } \\
\text { Wellington }\end{array}$ & 3 & 4 & 0 & 2 & $\begin{array}{l}\text { Near busy intersection } \\
\text { Wellington is } 4 \text { lanes wide with } \\
\text { trucks permitted } \\
\text { Traffic Volume: Medium } \\
\text { Road Type: Local, Collector }\end{array}$ \\
\hline 6253 & 43.256956 & -79.787178 & 1.51 & $\begin{array}{c}\quad 9 \\
(5<1.00) \\
(111.00-1.25) \\
(11.20-2.00) \\
\quad(2>2.00)\end{array}$ & $\begin{array}{l}\text { Burlington } \\
\text { Street E and } \\
\text { Parkdale } \\
\text { Avenue N }\end{array}$ & 0 & 3 & 5 & 1 & $\begin{array}{l}\text { Just West of ID } 7290 \\
\text { North of transport truck lot which } \\
\text { appears to be unpaved } \\
\text { Traffic Volume: High } \\
\text { Road Type: Collector, Arterial }\end{array}$ \\
\hline
\end{tabular}

A typical high $\mathrm{PM}_{2.5}$ Location can be seen in Figure 13 High PM2.5 Location Land Use 


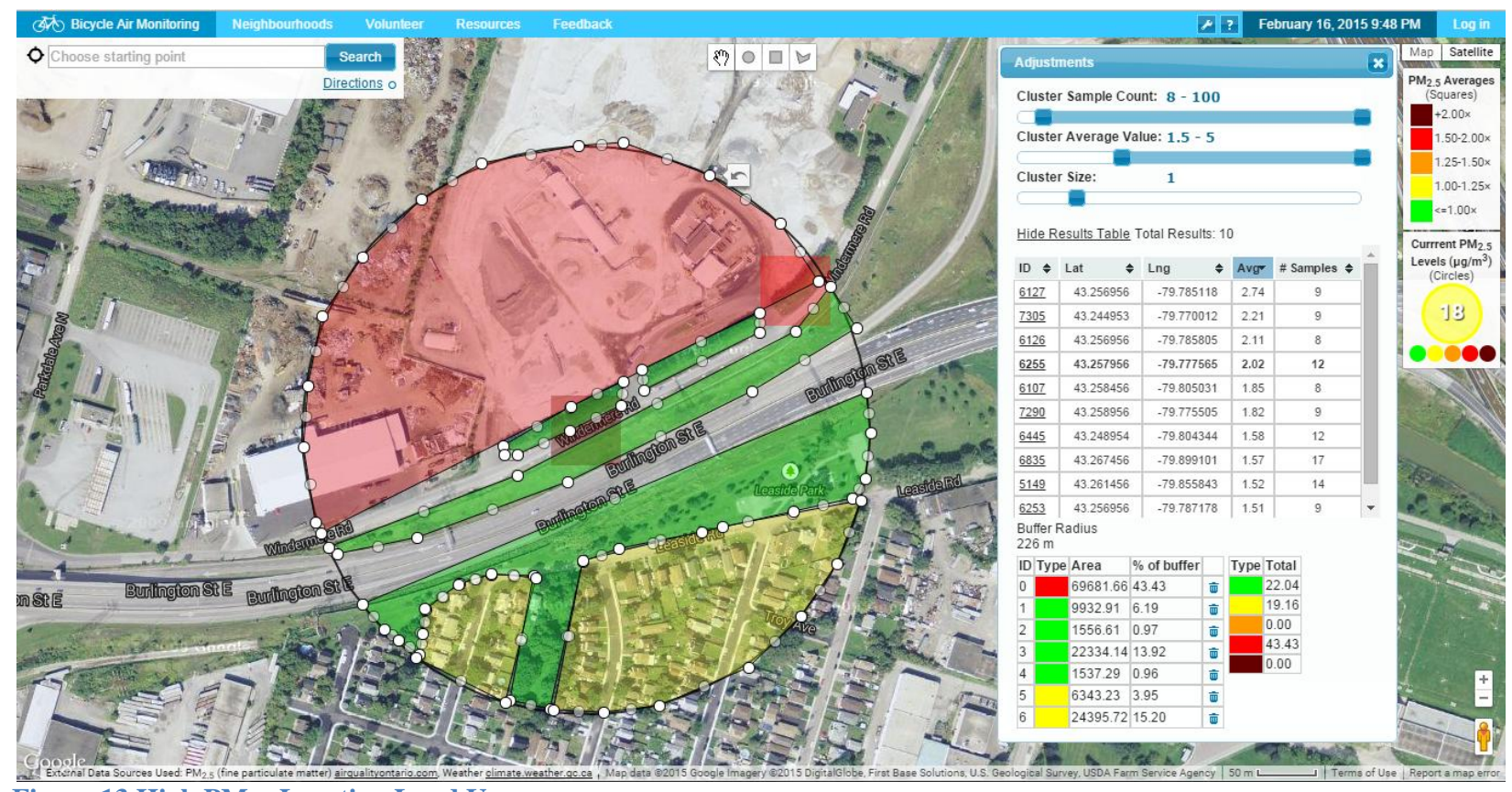

Figure 13 High $\mathrm{PM}_{2.5}$ Location Land Use

Figure 13 High PM2.5 Location Land Use shows a colorized view of land use within a buffer of $226 \mathrm{~m}$ from the center of the cluster. The colour choice for industrial, commercial, residential and vegetation was red, orange, yellow and green respectively. 


\subsection{Low $\mathrm{PM}_{2.5}$ Locations}

To identify areas with low levels of $\mathrm{PM}_{2.5}$ the adjustment controls were used, set with the following parameters; Cluster Sample Count: Min: 8, Cluster Average Value: Max: 0.64, Cluster

Size 1. A total of 10 clusters were found from all the samples collected. These clusters were sorted based on their Average $\mathrm{PM}_{2.5}$ levels (lowest to highest). The results uncovered from each of the locations can be found in

Table 4 Low PM2.5 Location Results.

Table 4 Low $\mathrm{PM}_{2.5}$ Location Results

\begin{tabular}{|c|c|c|c|c|c|c|c|c|c|c|}
\hline ID & Lat & Lng & Avg & $\begin{array}{c}\text { \# of } \\
\text { Samples } \\
\text { (Ranges) }\end{array}$ & $\begin{array}{l}\text { Nearest } \\
\text { Intersection }\end{array}$ & $\mathbf{R}$ & C & I & V & Observations \\
\hline 6067 & 43.265456 & -79.848976 & 0.55 & $\begin{array}{c}11 \\
(11<1.00)\end{array}$ & $\begin{array}{l}\text { Ferrie St E } \\
\text { and } \\
\text { Clark St }\end{array}$ & 5 & 1 & 0 & 1 & $\begin{array}{l}\text { South of demolition site at time of } \\
\text { street imaging } \\
\text { Traffic Volume: Low } \\
\text { Road Type: Local, Collector }\end{array}$ \\
\hline 6452 & 43.250454 & -79.811211 & 0.58 & $\begin{array}{c}10 \\
(9<1.00) \\
(11.00-1.25)\end{array}$ & $\begin{array}{c}\text { Barton St E } \\
\text { and Frederick } \\
\text { Ave }\end{array}$ & 4 & 5 & 0 & 1 & $\begin{array}{l}\text { Large new commercial district North } \\
\text { of cluster } \\
\text { Traffic Volume: Medium } \\
\text { Road Type: Local, Collector }\end{array}$ \\
\hline 6491 & 43.260956 & -79.852409 & 0.58 & $\begin{array}{c}13 \\
(13<1.00)\end{array}$ & $\begin{array}{l}\text { Barton St E } \\
\text { and } \\
\text { Victoria Ave } \\
\text { N }\end{array}$ & 7 & 2 & 0 & 2 & $\begin{array}{l}\text { Hospital on North West } \\
\text { Barton approaches median with trees } \\
\text { Traffic Volume: Medium } \\
\text { Road Type: Local, Collector }\end{array}$ \\
\hline 6240 & 43.265456 & -79.848289 & 0.60 & $\begin{array}{c}11 \\
(10<1.00) \\
(11.00-1.25)\end{array}$ & $\begin{array}{l}\text { Ferrie St E } \\
\text { and } \\
\text { Emerald St N }\end{array}$ & 5 & 1 & 0 & 2 & $\begin{array}{l}\text { Just East of ID } 6067 \\
\text { Large field on North East Corner } \\
\text { Traffic Volume: Low } \\
\text { Road Type: Local }\end{array}$ \\
\hline 6069 & 43.265956 & -79.846916 & 0.62 & $\begin{array}{c}12 \\
(11<1.00) \\
(11.00-1.25)\end{array}$ & $\begin{array}{c}\text { Mars Ave and } \\
\text { Douglas }\end{array}$ & 4 & 1 & 0 & 3 & $\begin{array}{l}\text { East of Cluster id } 6240 \\
\text { Large field on North East Corner } \\
\text { Traffic Volume: Low } \\
\text { Road Type: Local }\end{array}$ \\
\hline 6484 & 43.259456 & -79.846916 & 0.62 & $\begin{array}{c}14 \\
(11<1.00) \\
(111.00-1.25) \\
(11.50-2.00)\end{array}$ & $\begin{array}{l}\text { Barton St E } \\
\text { and } \\
\text { William St }\end{array}$ & 6 & 1 & 0 & 2 & $\begin{array}{l}\text { West on Barton approaches median } \\
\text { with small trees } \\
\text { Traffic Volume: Medium } \\
\text { Road Type: Local, Collector }\end{array}$ \\
\hline 6239 & 43.265956 & -79.851036 & 0.63 & $\begin{array}{c}11 \\
(10<1.00)\end{array}$ & $\begin{array}{l}\text { Ferrie St E } \\
\text { and }\end{array}$ & 1 & 3 & 0 & 3 & $\begin{array}{l}\text { Victoria has } 4 \text { lanes with a designated } \\
\text { bike lane and smooth road }\end{array}$ \\
\hline
\end{tabular}




\begin{tabular}{|c|c|c|c|c|c|c|c|c|c|c|}
\hline & & & & (1 $1.00-1.25)$ & $\begin{array}{c}\text { Victoria Ave } \\
\text { N }\end{array}$ & & & & & $\begin{array}{l}\text { North East corner appears to be a } \\
\text { large vacant field } \\
\text { Traffic Volume: Medium } \\
\text { Road Type: Local, Collector }\end{array}$ \\
\hline 7263 & 43.265456 & -79.849663 & 0.63 & $\begin{array}{c}\quad 9 \\
(8<1.00) \\
(11.00-1.25)\end{array}$ & $\begin{array}{l}\text { Ferrie St E } \\
\text { and } \\
\text { Clark St }\end{array}$ & 4 & 2 & 0 & 1 & $\begin{array}{l}\text { Just North of Cluster id } 6067 \\
\text { Traffic Volume: Medium } \\
\text { Road Type: Local, Collector }\end{array}$ \\
\hline 7264 & 43.265956 & -79.848289 & 0.63 & $\begin{array}{cl} & 10 \\
(9<1.00) \\
(1 & 1.00-1.25)\end{array}$ & $\begin{array}{l}\text { Ferrie St E } \\
\quad \text { and } \\
\text { Emerald St N }\end{array}$ & 5 & 1 & 0 & 1 & $\begin{array}{l}\text { Just West of Cluster id } 6240 \\
\text { Traffic Volume: Low } \\
\text { Road Type: Local }\end{array}$ \\
\hline 6062 & 43.266956 & -79.853783 & 0.64 & $\begin{array}{c}\quad 8 \\
(7<1.00) \\
(1 \quad 1.00-1.25)\end{array}$ & $\begin{array}{l}\text { Ferrie St E } \\
\text { and } \\
\text { Wellington St } \\
\mathrm{N}\end{array}$ & 3 & 2 & 0 & 5 & $\begin{array}{l}\text { Wellington is a } 1 \text { way street which } \\
\text { runs past an old railroad track } \\
\text { Traffic Volume: Medium } \\
\text { Road Type: Local, Collector }\end{array}$ \\
\hline
\end{tabular}

\section{A typical low $\mathrm{PM}_{2.5}$ Location can be seen in Figure 14 Low $\mathrm{PM}_{2.5}$ Location Land Use}

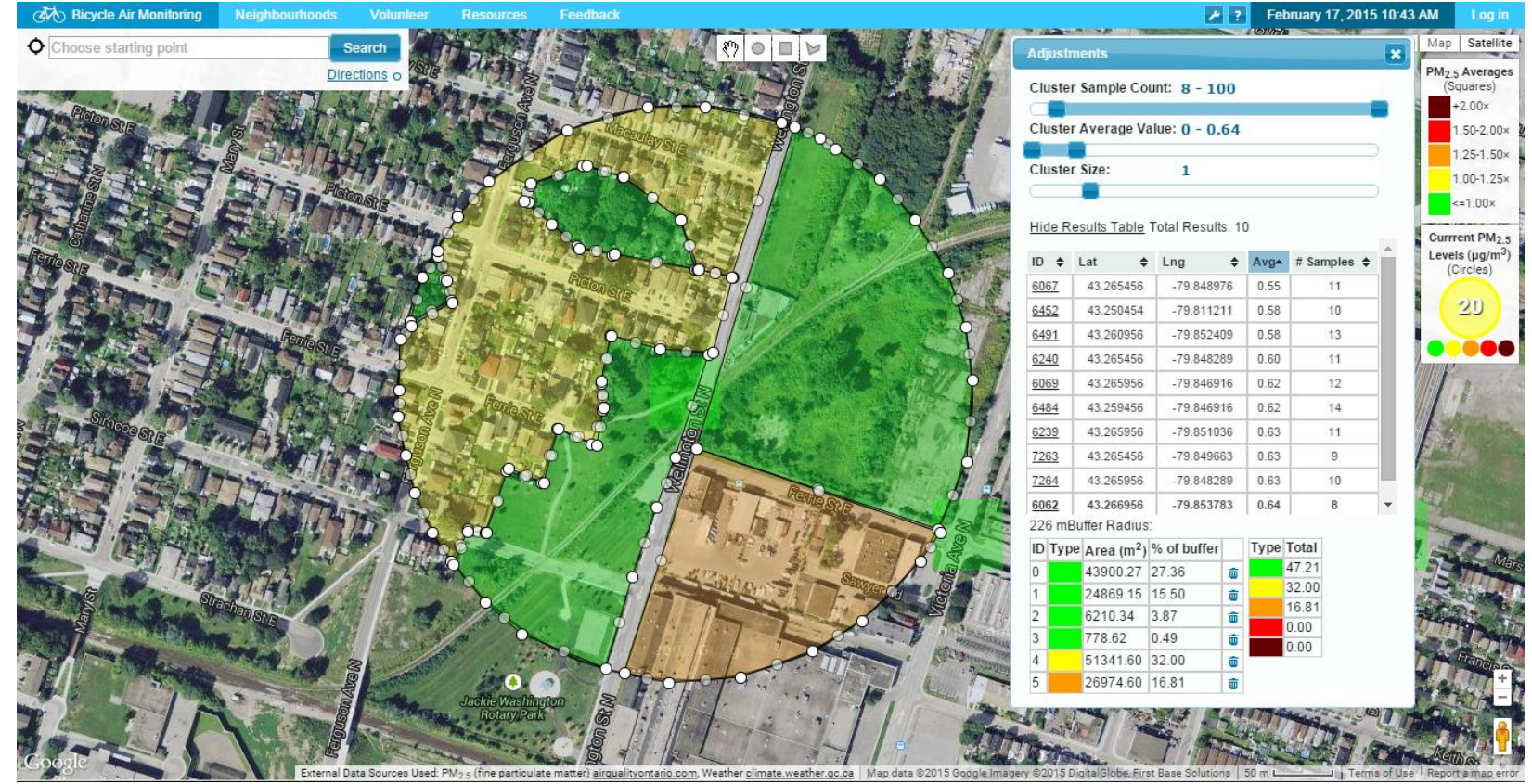

Figure 14 Low $\mathrm{PM}_{2.5}$ Location Land Use 


\subsection{Particulate Matter Sources}

After comparing the high $\mathrm{PM}_{2.5}$ locations to the low $\mathrm{PM}_{2.5}$ locations, it is apparent that road type and traffic volume are major factors in influencing the level of $\mathrm{PM}_{2.5}$ detected. The majority of high $\mathrm{PM}_{2.5}$ locations have perceived high traffic volumes and arterial roads within the buffer, while low $\mathrm{PM}_{2.5}$ locations have low and medium perceived traffic volumes and contain local and collector roads within their buffer. The land use between high $\mathrm{PM}_{2.5}$ locations and $\mathrm{PM}_{2.5}$ low locations is also fairly distinct as can been seen in Figure 15 Land Use Between High and Low PM Locations where 10 locations had their land use within the buffered averaged for both high and low PM locations.

\section{Land Use Between High and Low PM Locations}

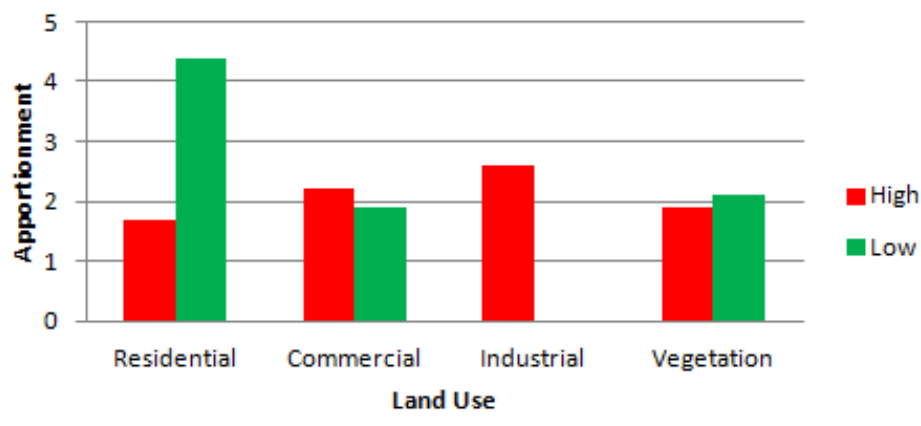

Figure 15 Land Use Between High and Low PM Locations

The absence of industrial land use is the most sticking criterion for low $\mathrm{PM}_{2.5}$ locations. These industrial locations are also next to high trafficked areas which have been identified to be a stronger influence on air pollution (Wallace, Corr, Deluca, Kanaroglou, \& McCarry, 2009). Interestingly, there appears to be comparable vegetation between high and low $\mathrm{PM}_{2.5}$ locations, though the characteristics of the vegetation are not being considered. Lastly, the increase in residential land use within low PM locations is promising given the amount of time one spends at 
home. This would also imply that residential land use is not a significant source of ground-level $\mathrm{PM}_{2.5}$.

It should be noted that 4 of the high $\mathrm{PM}_{2.5}$ locations were located near an underpass which suggests the air refresh is being impeded by the elevated road structure. As well, ID 6835 does not resemble the other clusters identified as high $\mathrm{PM}_{2.5}$ locations, though it is near a body of water potentially emitting humidity which is being detected by the Dylos unit.

For cyclists, the preliminary results demonstration that routes which incorporate local roads are likely to have cleaner air then busier roads such as arterials. This is likely due to the increased traffic volume on busier road along with the types of vehicle they support. It has been shown that the average $\mathrm{PM}_{2.5}$ emissions from a passenger car compared to a heavy-duty diesel truck are $6.6 \mathrm{mg} / \mathrm{km}$ and $325 \mathrm{mg} / \mathrm{km}$ respectively (USEPA Office of Transportation and Air Quality, 2008), (USEPA Office of Transportation and Air Quality, 2008). Though heavy-duty trucks represented only 1.5\% of on-road vehicles in Canada (Natural Resources Canada, 2009), their emissions account for $70 \%$ of $\mathrm{PM}_{2.5}$ for all vehicles (Campbell \& Gower, 2014). 


\section{Limitations}

There are a number of limitations present with is this study which include, the reliability of particle counts and GPS triangulation issues.

\subsection{Particle Composition}

The Dylos DC1700 offers the ability to detect particles in the air in two size ranges, though the composition of the measured particles remains unknown. As not all particles are created equal, having an understanding of whether a specific pollutant is present and at what concentration would be useful.

The omission of certain darker particles due to their ability to absorb light may affect detection performance of the optical laser sensor used in the Dylos AQM (Dye, 2014). This would result in the underestimation of particle counts from vehicular emissions since they use petroleum fuels.

The sensitivity to relative humidity demonstrated during the correlation investigation, could exaggerate the number or particles detected in locations near water versus those away from the water. This is an important consideration when viewing results which could skew route $\mathrm{PM}_{2.5}$ averages.

\subsection{Location Fidelity}

Pinpointing where a sample was measured is done by taking the time it was recorded and pairing the closest GPS location time. As the Dylos unit collects samples every 10 seconds, representing the average over that period, the GPS location at the midpoint 5 seconds earlier is used. Depending on the speed of the cyclist, the accuracy of this location will vary. For instance, if a cyclist is traveling at $10 \mathrm{~km} / \mathrm{h}$, each second they would cover $2 . \overline{7} \mathrm{~m}$. Over the 10 seconds it 
takes to generate a $\mathrm{PM}_{2.5}$ measurement, $27 . \overline{7} \mathrm{~m}$ would have been traveled and the point would be geolocated $13 . \overline{8} \mathrm{~m}$ earlier $\pm 2 . \overline{7} \mathrm{~m}$. However, if a cyclist is traveling at $30 \mathrm{~km} / \mathrm{h}$, they would cover $8 . \overline{3} \mathrm{~m}$ per second. Over 10 seconds they would have traveled $83 . \overline{3} \mathrm{~m}$ and their sample would be geolocated $41 . \overline{6} \mathrm{~m}$ earlier $\pm 8 . \overline{3} \mathrm{~m}$. As such the smallest cluster displayed to end users are $54 \times 54$ which would plot a point in every cluster for a bicyclist traveling at less than $19.44 \mathrm{~km} / \mathrm{h}$.

The accuracy of the GPS location is also in question. Though the manufacturer claims the unit can achieve an accuracy of up to $1.5 \mathrm{~m}$, there is no indication of how accurate each reading is. This inexactness of the GPS location should be reported as described by Goodchild and Li if it is to adhere to generally accepted scientific principles (Goodchild \& Li, 2012).

\subsection{GPS Unit Reliability}

There are a number of issues experienced while using the GPS device to geolocate samples, which include the inability to connect to satellites, the loss of connection due to overhead obstructions and worse, the mis-triangulation of locations. Tall buildings seem to block the GPS unit from connecting to satellites. This was experienced on several occasions when standing between two buildings. Traveling beneath underpasses has shown to prevent location triangulation (this would be resolved using interpolation between the last available location and

the next one retrieved). As well, at times during sample collection the points have strayed away from the actual location. During upload, these points can be identified and removed, though moving them to the actual location would be preferred, except such a solution would require strong evidence as to where the actual location exists. 


\section{Conclusion}

The BAM Map Engine aggregates $\mathrm{PM}_{2.5}$ measurements collected by volunteer bicyclists and makes this data publically available using an interactive map. Behind the scenes, the BAM Map Engine provides data management and analysis which supports the visualization of the data. Special consideration has been taken to ensure data is precompiled reducing web server processes and end-user download times. The choice of a grid-based clustering algorithm was used to summarize data at different zoom levels allowing users to drill-down through the data as they increase the map zoom level. A direction service was also built into the interactive map showing multiple bike routes along with the average $\mathrm{PM}_{2.5}$ levels for each route option. The aim of the direction service is to minimize a bicyclists exposure to air pollution by selecting the cleanest air route.

To assist with the analysis of the data, the ability to filter through the clusters of summary air quality data was made possible through the adjustment toolkit. Allowing the ability to indentify high and low air quality locations was demonstrated using the filters which underwent preliminary analysis. The use of a buffer placed around these locations along with basic observations of land-use begins to explain why such levels may have been detected. Recognizing that busier roads seem to be a common trend among higher levels of $\mathrm{PM}_{2.5}$ demonstrates the need to separate facilities targeting active and sensitive individuals such as bike lanes, daycares, schools, retirement homes, etc. As such policies would only influence future development, taking steps to avoid existing facilities placed near busier streets and other air polluting sources should be considered.

The concept of humans as sensors was explored, as the increased affordability of air quality measurement devices allows more individuals to get their hands on them. Understanding 
that fixed air quality monitors may not represent all the nuances of the surrounding neighbourhoods and that the more localized environment has the strongest influence on an individual's exposure, a more distributed air quality monitoring network is needed. The use of the Dylos Air Quality Monitor to collect ground level $\mathrm{PM}_{2.5}$ measurements reveals a snapshot of the air quality experienced, though the lack of sophistication of the optical sensor makes is prone to exaggerate measurements due to humidity and temperature on the one hand and underestimating darker particles on the other. This was demonstrated during a comparative analysis of the Dylos unit against a fixed air quality monitor, the 5030 SHARP.

While the BAM Map Engine provides the ability to see $\mathrm{PM}_{2.5}$ measurements and their location, the source of the $\mathrm{PM}_{2.5}$ detected is still left to guesswork. The ability to further analyse the composition of the air quality would allow for a pollutant breakdown which would assist in better identifying sources. Using more sophisticated air quality measuring devices would greatly improve source identification. As such analysis is a costly endeavour, being able to focus on priority areas is crucial, which is able to be afforded by the BAM Map Engine.

The BAM Map Engine demonstrates a method to manage VGI which is likely to continue to become a growing trend. The BAM Map Engine itself offers a model for other communities to monitor $\mathrm{PM}_{2.5}$ levels in their neighbourhoods to assist in identify chronically poor areas. As more data is collected, stronger results can be drawn able to better understand ground level $\mathrm{PM}_{2.5}$ exposure levels.

There are also a number of future projects which can be conducted to help further analyse the data collected during this project. While this study presents some preliminary results regarding factors affecting local air quality, a more systematic analysis would be useful to strengthen these findings. Recognizing air quality influences is of critical important to reduce 
human exposure and devise plans for air quality improvement. The ability to download the data using application programming interfaces (API's) would facilitate this further analysis by allowing specific parts of the dataset to be downloaded, such as by weather condition, time and location. Conducting a local hotspot analysis is one of many types of investigations capable of revealing statistically significant adverse air quality patterns within the data. The ability to combine downloaded data with other spatial statistics (such as road density, airports, industrial land use, etc), would support this further analysis of revealing the causal influences on air quality at a local level.

Support for alternative GPS devices with an accuracy value would assist with GPS location reliance. As many people have a GPS sensor in their smart phone capable of providing an accuracy value, allowing volunteers to use their phone with a standard GPS logger app installed would make this possible. Altering individual or multiple sample locations before upload could also improve data accuracy. This would involve positional adjustments, deletion and interpolation of locations when the GPS signal is clearly inaccurate or absent.

To advance the correlation analysis between the Dylos DC1700 unit with the fixed Thermo Scientific 5030 SHARP monitor, further sampling is required. As particle composition is a factor of its source, a correlation in Hamilton should be performed given the differing $\mathrm{PM}_{2.5}$ sources present compared to Toronto. Lastly, as the correlation samples were only collected during the winter, other seasons should be tested as well. 


\section{Appendix 1. Correlation Analysis Data Processing}

1. Download data from Dylos unit using Dylos Logger application.

2. Save file to location on local computer in text file format

3. Remove header information from text file and rename extension to .csv

4. Open file in excel

5. Add a new column for the real time

6. Copy the original time and adjust the seconds to match. The Dylos unit was 20 seconds fast, so by starting from first whole minute of samples (6) this time was reduced and the other samples that day were adjusted accordingly.

Note: For consistency, 6 samples were used for each minute average omitting beginning and trailing samples. As well, there appears to be a bug in the Dylos unit timestamp log as the data format changes form MM/DD/YY to DD/MM/YY when the DD $<=12$ and $M M<=12$. This was easily resolved in excel and incorporated into the BAM Map Engine prior to data uploading.

7. Two columns were added for averaging the small and large PM count measurements.

8. Two formulas were added at every whole minute averaging the previous six samples with formula =AVERAGE $($ cell $n: c e l l ~ n+5)$

9. Using the data filter function applied to the small average, and un-checking "Blanks", only the whole minute samples remained.

10. The whole minute samples were selected and copied to a new worksheet

11. The minute samples from the 5030 SHARP unit terminal were then aligned to the whole minute Dylos sample averages 
12. The closest weather information was also added to the worksheet, available in 1 hour averages. Two weather stations were identified, one west $(\sim 7.3 \mathrm{~km}$ away) and one east ( 6.1 km away) of the location. 


\section{Bibliography}

American Academy of Pediatrics. (2004). Ambient Air Pollution: Health Hazards to Children. Pediatrics, 114, 1699-1707.

American Lung Association. (2005, October 14). Backgrounder: What is Particulate Matter? Retrieved Februrary 13, 2015, from Vermont Department of Environmental Conservation Air Quality \& Climate Division: http://www.vtwoodsmoke.org/pdf/ALAParticulate.pdf

AQICN. (2013, October 21). Dylos Air Particule Conter experiment maintenance. Retrieved October 2014, 2014, from AQICN: http://aqicn.org/faq/2013-10-21/dylos-air-particuleconter-experiment-maintenance/

AQICN. (2014). The Dylos experiment: Real-time Air Quality readings from Beijing. Retrieved December 17, 2014, from AQICN: http://aqicn.org/sensor/beijing/sanlitun/

Banister, D. (2011, November 7). Sustainable Transport and Public Policy. Retrieved from GCI: http://www.gci.org.uk/Documents/E6-40-04-021.pdf

Ban-Weiss, G., Mclaughlin, J., Harley, R., Kean, A. G., \& Grosjean, D. (2008). Carbonyl and Nitrogen Dioxide Emissions From Gasoline- and Diesel-Powered Motor Vehicles. Environmental Science \& Technology, 42, 3944-3950.

Bhatt, S. P., \& Dransfield, M. T. (2013). Chronic obstructive pulmonary disease and cardiovascular disease. Translational Research, 162, 237-251.

Brook, R. D., Rajagopalan, S., III, C. A., Brook, J. R., Bhatnagar, A., Diez-Roux, A. V., . . . Kaufman, J. D. (2010, June 1). Particulate Matter Air Pollution and Cardiovascular Disease. Retrieved from American Heart Association: http://circ.ahajournals.org/content/121/21/2331.full.pdf

Brugge, D., Durant, J. L., \& Rioux, C. (2007, August 9). Near-highway pollutants in motor vehicle exhaust: A review of epidemiologic evidence of cardiac and pulmonary health risks. Retrieved February 13, 2015, from Environmental Health Jounal: http://www.ehjournal.net/content/6/1/23

Campbell, M., \& Gower, S. (2014, April 11). Path to Healthier Air: Toronto Air Pollution Burden of . Retrieved May 23, 2014, from City of Toronto: http://www.toronto.ca/legdocs/mmis/2014/hl/bgrd/backgroundfile-68506.pdf

Canadian Broadcasting Corporation. (2008, March 4). Majority of Toronto commuters still get in cars to get to work: census. Retrieved August 5, 2014, from Canadian Broadcasting Corporation: http://www.cbc.ca/news/canada/toronto/majority-of-toronto-commutersstill-get-in-cars-to-get-to-work-census-1.701205

Candian Medical Association. (2008). No Breathing Room National Illness Costs of Air Pollution. Ottawa: Candian Medical Association.

Cerveny, R. S., \& Balling, J. R. (1998). Weekly cycles of air pollutants, precipitation and tropical cyclones in the coastal NW Atlantic region. United Kingdom: Nature.

Cheng, Z., Jiang, J., Fajardo, O., Wang, S., \& Hao, J. (2013). Characteristics and health impacts of particulate matter pollution in China. Atmospheric Environment, 65, 186-194.

City of Toronto. (2000). A Transportation Vision for the City of Toronto Official Plan. Toronto: Urban Development Services.

City of Toronto. (2001). City of Toronto Bike Plan. Retrieved May 14, 2014, from City of Toronto: https://www1.toronto.ca/City\%200f\%20Toronto/Transportation\%20Services/Cycling/Fil es/pdf/B/bike_plan_full.pdf 
City of Toronto. (2009). Changing Gears Toronto for Cyclists. Retrieved May 14, 2014, from City of Toronto:

http://www1.toronto.ca/city_of_toronto/transportation_services/cycling/files/pdf/changin g_gears_book.pdf

Clean Air Hamilton. (2014). Where Does Pollution Go? Retrieved November 20, 2014, from Clean Air Hamilton: http://www.cleanair.hamilton.ca/default.asp?id=82

Clear Air Hamilton. (2013, December). Report of the Air Quality Task Force (AQTF) Hamilton Area Airshed. Retrieved September 5, 2014, from Clear Air Hamilton: http://www.cleanair.hamilton.ca/downloads/AQTF\%20Action\%20Plan.pdf

Columbus GPS. (2011, September 7). V-990 Mulitfunctional GPS Data logger. Retrieved November 28, 2014, from Columbus GPS: http://www.columbusgps.de/download/columbus_v-990_manual_v1.0.pdf

Comber, A., See, L., Fritz, S., Velde, M. V., Perger, C., \& Foody, G. (2013). Using control data to determine the reliability of volunteered geographic information about land cover. International Journal of Applied Earth Observation and Geoinformation, 23, 37-48.

Crawford, G. (2012, July 31). Environment Hamilton 10 year Anniversary. Retrieved November 26, 2014, from Youtube:

https://www.youtube.com/watch?feature=player_embedded \&v=q2kMtLnqRNI

DEFRA: Air Quality Expert Group. (2005, June 14). What is particulate matter? Retrieved February 10, 2015, from DEFRA: http://ukair.defra.gov.uk/assets/documents/reports/aqeg/ch2.pdf

Dye, T. (2014, May 31). Air Quality Sensors: How Good is Good Enough? Retrieved January 8, 2015, from Make: http://makezine.com/2014/05/31/air-quality-sensors-how-good-isgood-enough/

Dylos Corporation. (2012, November 1). User's Guide DylosLogger Software Version 1.6. Retrieved December 12, 2014, from Dylos Products: http://lib.store.yahoo.net/lib/yhst16473542037836/dyloslogger16.zip

Dylos Corporation. (2014). DC1700 Battery Operated AQM. Retrieved 8 August, 2014, from Dylos Corporation: http://www.dylosproducts.com/dc1700.html

Ehrgott, M., Wanga, J. Y., Raith, A., \& Houtte, C. v. (2012). A bi-objective cyclist route choice model. Transportation Research, 46, 652-663.

Employment and Social Development Canada. (2012). Health - Obesity. Retrieved June 16, 2014, from Employment and Social Development Canada: http://www4.hrsdc.gc.ca/.3ndic.1t.4r@-eng.jsp?iid=6\#M_1

Employment and Social Development Canada. (2012). Health - Physical Activity. Retrieved June 16, 2014, from Employment and Social Development Canada: http://www4.hrsdc.gc.ca/.3ndic.1t.4r@-eng.jsp?iid=8

Environment Canada. (2012, March 29). RCC Environment Working Group: Particulate Matter (Air Pollutants) Work Plan. Retrieved November 21, 2014, from Action Plan Ontario: http://actionplan.gc.ca/grfx/BAPRCC/Particulate_Matter_Air_Pollutants_Work_Plan.pdf

Environment Canada. (2013, August 14). Canadian Ambient Air Quality Standards. Retrieved November 21, 2014, from Environment Canada: http://www.ec.gc.ca/default.asp?lang=En\&n=56D4043B-1\&news=A4B2C28A-2DFB4BF4-8777-ADF29B4360BD 
Environment Canada. (2013, August 14). Canadian Ambient Air Quality Standards. Retrieved October 3, 2014, from Environment Canada:

http://www.ec.gc.ca/default.asp?lang=En\&n=56D4043B-1\&news=A4B2C28A-2DFB4BF4-8777-ADF29B4360BD

Environment Hamilton. (2014). EH History and Accomplishments. Retrieved November 26, 2014, from Environment Hamilton:

http://environmenthamilton.org/view/page/history_accomplishments

Environment Hamilton. (2014). http://environmenthamilton.org/view/page/BAM. Retrieved August 6, 2014, from Environment Hamilton:

http://environmenthamilton.org/view/page/BAM

Environmental Commissioner of Ontario. (2011, August 23). Air Quality Monitoring and Reporting in Ontario - Fostering a False Sense of Security. Retrieved November 21, 2014, from Eco Issues:

http://www.ecoissues.ca/index.php?title=Air_Quality_Monitoring_and_Reporting_in_On tario_\%E2\%80\%93_Fostering_a_False_Sense_of_Security

Environmental Commissioner of Ontario. (2015, January 20). Filling the Gaps in the Regulation of Fine Particular Matter. Retrieved from Environmental Commissioner of Ontario: http://www.ecoissues.ca/index.php/Filling_the_Gaps_in_the_Regulation_of_Fine_Partic ular_Matter

Environmental Protection Agency. (2006, October 17). National Ambient Air Quality Standards for Particulate Matter; Final Rule. Retrieved from Environmental Protection Agency: http://www.epa.gov/ttnamti1/files/ambient/pm25/pt5006.pdf

European Commission. (2014, October 30). Air Quality Standards. Retrieved November 20, 2014, from European Commission: http://ec.europa.eu/environment/air/quality/standards.htm

Goodchild, M. F. (2007). Citizens as Sensors: The World of Volunteered Geography. GeoJournal, 69, 211-221.

Goodchild, M. F., \& Li, L. (2012). Assuring the quality of volunteered geographic information. Spatial Statistics, 1, 110-120.

Government of Canada. (2012, December 10). Road traffic and air pollution. Retrieved October 2, 2014, from Government of Canada: http://healthycanadians.gc.ca/healthy-living-viesaine/environment-environnement/outdoor-air-exterieur/traf-eng.php

Health Canada. (2013, June 24). National Ambient Air Quality Objectives For Particulate Matter. Retrieved October 2, 2014, from Health Canada: http://www.hc-sc.gc.ca/ewhsemt/pubs/air/naaqo-onqaa/particulate_matter_matieres_particulaires/summarysommaire/index-eng.php

Johnson, M. F., Hannah, C., Acton, L., Popovici, R., Karanth, K. K., \& Weinthal, E. (2014). Network environmentalism: Citizen scientists as agents for environmental advocacy. Global Environmental Change, 29, 235-245.

Kelly, F. J., \& Fussell, J. C. (2012). Size, source and chemical composition as determinants of toxicity attributable to ambient particulate matter. Atmospheric Environment, 60, 504526.

Kenneth Y, C., \& Greenstones, M. (1998). Does Air Quality Matter? Cambridge: National Bureau of Economic Research.

Klinkenberg, B. (2015). Citizen Science And Volunteered Geographic Information: Can These Help In Biodiversity Studies? Retrieved from University of British Columbia Department 
of Geography: http://ibis.geog.ubc.ca/biodiversity/VGI--

VolunteerGeographicInformation.html

Langner, M., Draheim, T., \& Endlicher, W. (2011). Particulate Matter in the Urban Atmosphere: Concentration, Distribution, Reduction - Results of Studies in the Berlin Metropolitan Area. Berlin: Humboldt-Universit€at zu Berlin.

Liberti, A. (1975). Modern Methods for Air Pollution Monitoring. Pure and Applied Chemistry, 10, 519-534.

McPherson, E. G., Nowak, D. J., \& Rowntree, R. (1994). Air pollution removal by Chicago's urban forest. Chicago: United States Department of Agriculture.

Ministry of the Environement and Climate Change. (2010). Current Pollutant Concentrations. Retrieved August 8, 2014, from Ministry of the Environement and Climate Change: http://www.airqualityontario.com/history/summary.php

Ministry of the Environment. (2012, April). Ontario's Ambient Air Quality Criteria. Retrieved from Air Quality Ontario: http://www.airqualityontario.com/downloads/AmbientAirQualityCriteria.pdf

Minstry of the Environment and Climate Change. (2010). Fine Particulate Matter. Retrieved December 11, 2014, from Minstry of the Environment and Climate Change: http://www.airqualityontario.com/science/pollutants/particulates.php

Mitra, R., \& Faulkner, G. (2012). There's no such thing as bad weather, just the wrong clothing: Climate, weather and active school transportation in Toronto, Canada. Canadian Journal of Public Health, 103, 35-41.

Moore, D. K., Jerrett, M., Mack, W. J., \& Künzli, N. (2007). A land use regression model for predicting ambient fine particulate matter across Los Angeles, CA. Journal of Environmental Monitoring(3), 246-252.

Morawska, L., Thomas, S., Gilbert, D., Greenaway, C., \& Rijnders, E. (1999). A study of the horizontal and vertical profile of submicrometer particles in relation to a busy road. Atmospheric Environment, 33(8), 1261-1274.

National Oceanic and Atmospheric Administration. (2008, March 25). Nonpoint Source Pollution : Atmospheric Inputs. Retrieved Noverber 19, 2014, from National Oceanic and Atmospheric Administration: http://oceanservice.noaa.gov/education/kits/pollution/07input.html

Natural Resources Canada. (2009). Canadian Vehicle Survey. Retrieved June 15, 2014, from Natural Resources Canada: http://oee.nrcan.gc.ca/publications/statistics/cvs09/pdf/cvs09.pdf

Ontario Ministry of the Environment and Climate Change. (2014). Frequently Asked Questions. Retrieved November 20, 2014, from Air Quality Ontario: http://www.airqualityontario.com/press/faq.php\#pm25how

OpenStreetMap. (2015). http://www.openstreetmap.org/about. Retrieved from OpenStreetMap: http://www.openstreetmap.org/about

Paskaleva, K. A. (2009). Enabling the smart city: the progress of city e-governance in Europe. Innovation and Regional Development, 1, 405-421.

Pengnate, S. (2013). Essays on the influence of website emotional design features on users' emotional and behavioral responses. Stillwate: Oklahoma State University.

Pope, C. A., \& Dockery, D. W. (2006). Health Effects of Fine Particulate Air Pollution: Lines that Connect. Journal of the Air \& Waste Management Association, 56, 709-742. 
Ride the City. (2014). Ride the City Toronto. Retrieved August 6, 2014, from Ride the City: http://www.ridethecity.com/toronto

Ronan. (2014, June 16). Dylos Air Particule Counter Experimentation. Retrieved December 17, 2013, from GitHub: https://github.com/aqicn/dylos

Ross, Z., Jerrett, M., Ito, K., Tempalski, B., \& Thurston, G. D. (2007). A land use regression for predicting fine particulate matter concentrations in the New York City region. Atmospheric Environment, 41(11), 2255-2269.

Rotek Environmental Inc. (2011). Mobile Air Quality Monitoring to Determine Local Impacts. Hamilton: City of Hamilton.

Sæbø, A., Popek, R., Nawrot, B., Hanslin, H., Gawronska, H., \& Gawronski, S. (2012). Plant species differences in particulate matter accumulation on leaf surfaces. Science of the Total Environment, 427-428, 347-354.

Sarah Jarjour, M. J. (2013). Cyclist route choice, traffic-related air pollution, and lung function: a scripted exposure study. Berkeley: Environmental Health.

Schwarze, P., Øvrevik, J., M La ${ }^{\circ}$, M. R., Nafstad, P., Hetland, R., \& Dybing, E. (2006). Particulate matter properties and health effects: consistency of epidemiological and toxicological studies. Human \& Experimental Toxicology, 25, 559-579.

Semple, S., Apsley, A., \& MacCalman, L. (2012). An inexpensive particle monitor for smoker behaviour modification in homes. Edinburgh: University of Aberdeen.

SENES Consultants Limited. (2012). HEALTH IMPACTS EXPOSURE TO OUTDOOR AIR POLLUTION IN HAMILTON, ONTARIO. Hamilton : Clean Air Hamilton; Hamilton Public Health Services.

Strauss, J. (2012). Cyclist Injury Risk and Pollution Exposure at Urban Signalized Intersections. Montreal: McGill University.

Sua, J. G., Winters, M., Nunes, M., \& Brauer, M. (2010). Designing a route planner to facilitate and promote cycling in Metro Vancouver, Canada. Transportation Research Part A. Vancouver: Transportation Research.

Thai, A., McKendry, I., \& Brauer, M. (2008). Particulate matter exposure along designated bicycle routes in Vancouver, British Columbia. Science of the Total Environement, 405(1-3), $26-35$.

Thermo Scientific. (2015). 5030 SHARP Monitor. Retrieved February 5, 2015, from Thermo Scientific: http://www.thermoscientific.com/content/tfs/en/product/5030-sharpmonitor.html

United Nation Economic Commission for Europe. (2014). Convention on Long-range Transboundary Air Pollution. Retrieved November 21, 2014, from United Nation Economic Commission for Europe: http://www.unece.org/env/lrtap/

United Nations. (2009). Pollutants: Particulate matter (PM). Retrieved November 19, 2014, from United Nations Environmental Program: http://www.unep.org/tntunep/toolkit/pollutants/facts.html

United Stated Environmental Protection Agency. (2005, February 8). Understanding Particle Pollution. Retrieved November 19, 2014, from United Stated Environmental Protection Agency: http://www.epa.gov/airtrends/aqtrnd04/pmreport03/pmunderstand_2405.pdf

United States Environmental Protection Agency Office of Transportation and Air Quality. (2008). Average Annual Emissions and Fuel Consumption for Gasoline-Fueled Passenger Cars and Light Trucks. Washington: United States Environmental Protection Agency Office of Transportation and Air Quality. 
United States Environmental Protection Agency Office of Transportation and Air Quality. (2008). Average In-Use Emissions from Heavy-Duty Trucks. Washington: United States Environmental Protection Agency Office of Transportation and Air Quality.

United States Environemental Protection Agency. (2013, March 18). Particulate Matter (PM). Retrieved August 8, 2014, from United States Environemental Protection Agency: http://www.epa.gov/airquality/particlepollution/

United States Environmental Protection Agency. (2012, December 21). Revised Air Quality Standards for Particle Pollution And Updates to the Air Quality Index (AQI). Retrieved November 20, 2014, from United States Environmental Protection Agency: http://www.epa.gov/airquality/particlepollution/2012/decfsstandards.pdf

United States Environmental Protection Agency. (2012, April 20). Six Common Air Pollutants. Retrieved August 9, 2014, from United States Environmental Protection Agency: http://www.epa.gov/airquality/urbanair/

Vardoulakis, S., Fisher, B. E., \& Gonzalez-Flesca, N. (2003). Modelling Air Quality in Street Canyons: A Review. Atmospheric Environment, 37(2), 155-182.

Vaz, E., \& Arsanjani, J. J. (2015). Crowdsourced mapping of land use in urban dense environments: An assessment of Toronto. The Canadian Geographer, 1-10.

Vaz, E., \& Jokar Arsanjani, J. (2015). Predicting Urban Growth of the Greater Toronto Area Coupling a Markov Cellular. Journal of Environmental. Informatics, 1-30.

Wallace, J., Corr, D., Deluca, P., Kanaroglou, P., \& McCarry, B. (2009). Mobile monitoring of air pollution in cities: the case of Hamilton, Ontario, Canada. Environmental Monitoring, $11,998-1003$.

Wallace, J., Corr, D., Deluca, P., Kanaroglou, P., \& McCarry, B. (2009). Mobile monitoring of air pollution in cities: the case of Hamilton, Ontario, Canada. Environmental Monitoring, 998-1003.

Wolff, H., \& Perry, L. (2010, May 1). Trends in Clean Air Legislation in Europe: Particulate Matter and Low Emission Zones. Retrieved November 21, 2014, from University of Washington: http://faculty.washington.edu/hgwolff/REEP.pdf

World Health Orgniazation. (2005). Air Quality Guidelines Global Update. Copenhagen: WHO Regional Offi ce for Europe.

World Heath Organization. (2014, March). Ambient (outdoor) air quality and health. Retrieved November 10, 2014, from World Heath Organization: http://www.who.int/mediacentre/factsheets/fs313/en/

Yang, S. (2012, October 22). Air pollution study clears the air on diesel versus gas emissions. Retrieved October 5, 2014, from UC Berkeley News Center: http://newscenter.berkeley.edu/2012/10/22/diesel-vs-gas-contributing-to-smog/

Zhang, L., Michelangeli, D. V., \& Taylor, P. A. (2004). Numerical studies of aerosol scavenging by low-level, warm stratiform clouds and precipitation. Atmospheric Environment, 38(28), 4653-4665.

Zuurbier, M., Hoek, G., Oldenwening, M., Lenters, V., Meliefste, K., Hazel, P. v., \& Brunekreef, B. (2010). Commuters' Exposure to Particulate Matter Air Pollution Is Affected by Mode of Transport, Fuel Type, and Route. Environmental Health Perspectives, 118, 783-789. 